\title{
Role of trehalose in heat and desiccation tolerance in the soil bacterium Rhizobium etli
}

\author{
Mercedes Reina-Bueno ${ }^{1 \dagger}$, Montserrat Argandoña $^{1 \dagger}{ }^{\dagger}$, Joaquín J Nieto ${ }^{1}$, Alba Hidalgo-García ${ }^{3}$, \\ Fernando Iglesias-Guerra ${ }^{2}$, María J Delgado ${ }^{3}$ and Carmen Vargas ${ }^{1 *}$
}

\begin{abstract}
Background: The compatible solute trehalose is involved in the osmostress response of Rhizobium etli, the microsymbiont of Phaseolus vulgaris. In this work, we reconstructed trehalose metabolism in $R$. etli, and investigated its role in cellular adaptation and survival to heat and desiccation stress under free living conditions.

Results: Besides trehalose as major compatible solute, R. etli CE3 also accumulated glutamate and, if present in the medium, mannitol. Putative genes for trehalose synthesis (otsAB/treS/treZY), uptake (aglEFGK/thuEFGK) and degradation (thuAB/treC) were scattered among the chromosome and plasmids p42a, p42c, p42e, and p42f, and in some instances found redundant. Two copies of the ots A gene, encoding trehalose-6-P-synthase, were located in the chromosome (ots $A c h$ ) and plasmid p42a (otsAa), and the latter seemed to be acquired by horizontal transfer. High temperature alone did not influence growth of $R$. etli, but a combination of high temperature and osmotic stress was more deleterious for growth than osmotic stress alone. Although high temperature induced some trehalose synthesis by $R$. etli, trehalose biosynthesis was mainly triggered by osmotic stress. However, an otsAch mutant, unable to synthesize trehalose in minimal medium, showed impaired growth at high temperature, suggesting that trehalose plays a role in thermoprotection of $R$. etli. Desiccation tolerance by $R$. etli wild type cells was dependent of high trehalose production by osmotic pre-conditioned cells. Cells of the mutant strain otsAch showed ca. 3-fold lower survival levels than the wild type strain after drying, and a null viability after 4 days storage.
\end{abstract}

Conclusions: Our findings suggest a beneficial effect of osmotic stress in $R$. etli tolerance to desiccation, and an important role of trehalose on the response of $R$. etli to high temperature and desiccation stress.

\section{Background}

Rhizospheric rhizobia are subjected to fluctuating osmotic, heat and drought stresses due to the succession of drought and rain periods, the exclusion of salts like $\mathrm{NaCl}$ from root tissues, the release of plant exudates, or the production of exopolymers by plant roots and other rhizobacteria. In addition, rhizobia must also adapt to osmotic and oxidative stresses during the infection process and in a nodule exchanging nutrients with the host plant. On the other hand, drought stress is particularly important when rhizobia are used as inoculants for legumes, since it affects cell viability during storage in carrier-based (i.e. seed-coated) inoculants

\footnotetext{
*Correspondence: cvargas@us.es

${ }^{\dagger}$ Equal contributors

'Department of Microbiology and Parasitology, Faculty of Pharmacy, University of Seville, Profesor García González 2, Seville 41012, Spain Full list of author information is available at the end of the article
}

$[1,2]$. Therefore, besides symbiotic efficiency, improvement of survival of rhizobia under conditions of the above abiotic constraints may constitute a competitive trait for either native or inoculant rhizobia, to persist in soil and solid inoculant formulations, and to improve the colonization and/or infection process. The responses to osmotic, drought and heat stress in bacteria involve very complex adaptation mechanisms, but one common element of the three responses is the synthesis of protectant molecules named compatible solutes [3]. Indeed, the role of compatible solutes goes beyond osmotic adjustment alone to protection of cells and cell components from freezing, desiccation, high temperature, and oxygen radicals, as well as to serve as sources of carbon, energy and nitrogen [4].

Trehalose $(O-\alpha,-\mathrm{D}$-glucosyl-[1 $\rightarrow 1]-\alpha-\mathrm{D}$-glucoside) has been found as the main compatible solute in almost any rhizobial strain tested so far, and its accumulation 
has been detected in free-living cells, bacteroids, and nodules [2,5-8]. Trehalose accumulation by $R$. leguminosarum bv trifolii and Sinorhizobium meliloti reaches its maximal levels at stationary phase of growth $[5,7,9]$. Out of the five different routes known for trehalose biosynthesis, three pathways have been found in rhizobia. First, the OtsA-OtsB route, which is very well conserved among insects, plants, fungi and bacteria, involves the transfer of glucose from UDP-glucose to glucose-phosphate to form trehalose-6-phosphate by trehalose-6-phosphate synthase (OtsA). Then, a trehalose6-phosphate phosphatase (OtsB) dephosphorylates this intermediate to produce trehalose $[2,5,7,10]$. Second, trehalose synthase (TreS), first described in mycobacteria [11], catalyzes the reversible conversion of maltose and trehalose. In the case of Bradyrhizobium japonicum, trehalose is accumulated to a greater extent in a treS mutant, suggesting that TreS is involved in trehalose degradation to maltose [2]. A third pathway first discovered in Rhizobium sp. M-11 [12] and the archaeon Sulfolobus acidocaldarius [13], converts the terminal unit of a linear maltodextrin (e.g., glycogen or starch) to trehalose via maltooligosyl trehalose synthase, encoded by tre $Y$, and maltooligosyl trehalose trehalohydrolase (TreZ).

Apart from stress protectant, trehalose also serves as a carbon and energy source for many bacteria, including rhizobia. In soil, trehalose originates from nodules during nodule senescence [14] and as an excretion product from fungi [15]. There are several known pathways for trehalose catabolism in microorganisms. The major enzyme involved in the turnover of trehalose, trehalase ( $\alpha, \alpha, 1,1$-glucosyl hydrolase), usually belongs to families 37 and 15 of glycoside hydrolases [16,17]. In other cases, trehalose degradation involves a trehalose phosphorylase (TreP) [18]. Degradation of trehalose-6-phosphate can be mediated by a trehalose 6-phosphate hydrolase (TreC), belonging to family 13 of glycoside hydrolases [16], or a trehalose-6-phosphate phosphorylase (TrePP) [19].Trehalase, trehalose phosphorylase, and trehalose-6phosphate hydrolase were detected in soybean nodules formed by B. japonicum [20], but orthologous genes for these enzymes were not found in the genome of $S$. meliloti [21]. In the former species, two ABC transport systems (ThuEFGK and AglEFGAK), and one major catabolic pathway (ThuAB) have been reported for trehalose [22,23].

In rhizobia, the effect of trehalose accumulation on tolerance to osmotic and drought stress, as well as symbiotic performance, appears to be dependent on the particular stress, the rhizobial species, and the host genotype. Regarding osmotic stress, OtsAB seems to play a major role in trehalose accumulation under hyperosmotic conditions, and it is the main system involved in osmoadaptation of S. meliloti [5] and B. japonicum [2]. In addition, accumulated trehalose seems to have a major role in protecting B. japonicum [24] and $R$. leguminosarum bv trifolii [7] against desiccation stress. With respect to symbiotic phenotype, in B. japonicum trehalose accumulation is involved in the development of symbiotic nitrogen-fixing root nodules on soybean plants [2]. In contrast, in other rhizobia such as $R$. leguminosarum bv trifolii or S. meliloti, trehalose accumulation has been proposed to be important only for competitiveness [5,7]. The role of trehalose as thermoprotectant has been established in yeast [25] and bacteria such as E. coli [26], Salmonella enterica serovar Typhimurium [27] or the halophilic bacterium Chromohalobacter salexigens [28]. However the role of trehalose in protection against heat stress in rhizobia has not yet been investigated.

Common bean (Phaseolus vulgaris) is an important crop in the diet of people of Latin America. In this region, it is mainly nodulated by $R$. etli [29]. The complete genome sequence of $R$. etli CFN 42 has been reported (http://www.ccg.unam.mx/retlidb/) [30]. It contains more replicons (a circular chromosome and six large plasmids) than any other completely sequenced nitrogen-fixing bacterium, but several pieces of evidence suggest an exogenous origin for plasmids p42a and $\mathrm{p} 42 \mathrm{~d}$

Suarez and co-workers [10] reported an ots $A$ mutant still capable of accumulating trehalose to a certain extent, which was nevertheless osmosensitive and displayed reduced nodulation and lower nitrogenase activity, and consequently reduced plan biomass. In contrast, an OtsA overexpressing $R$. etli strain showed increased trehalose content and was more tolerant to osmotic stress than the wild-type. Bean plants inoculated with the OtsA overexpressing strain showed improved nodulation and nitrogen fixation, and increased drought tolerance. In addition, transcriptomic analysis of plant nodules in symbiosis with the OtsA overexpressing strain revealed induction of several genes involved in stress tolerance, and carbon and nitrogen metabolism, suggesting that trehalose (or a trehalose derivative) plays a role as a signal molecule from rhizobia to the legume nodule [10].

Whereas increased trehalose levels in $R$. etli inoculant strains seem to favor drought tolerance of the host legume, the involvement of trehalose in desiccation tolerance of $R$. etli free-living cells has not been investigated. In this work, we address the role of trehalose in heat and desiccation tolerance of this soil bacterium. Based on genome analysis, we reconstructed the $R$. etli trehalose metabolism, and found evidence for a horizontal transfer origin of the ots $A$ copy located in plasmid p42a. In addition, we showed that inactivation of the chromosomal copy of ots $A$ (otsAch) completely abolishes trehalose synthesis by $R$. 
etli in mannitol minimal medium. Finally, we showed an important role for trehalose in thermoprotection and desiccation tolerance of $R$. etli free-living cells.

\section{Methods}

\section{Bacterial strains, plasmids and culture conditions}

The bacterial strains and plasmids used are listed in Table 1. R. etli CE3 (a spontaneous $\mathrm{Sm}^{\mathrm{r}}$ mutant of R. etli CFN $42^{\mathrm{T}}$ ) [31] was used as the wild type strain. $R$ etli strains were routinely grown in complex TY medium [32]. E. coli strains were grown aerobically in complex LB medium [33]. B'medium [34], which contains $10 \mathrm{~g} \mathrm{l}^{-}$ ${ }^{1}$ mannitol as the sole carbon source, was used as minimal medium for $R$. etli. When appropriate, trehalose and glucose were also used as carbon source at a final concentration of $20 \mathrm{mM}$. Osmotic strength of this

Table 1 Bacterial strains and plasmids used in this study

\begin{tabular}{|c|c|c|}
\hline Strain or plasmid & $\begin{array}{l}\text { Relevant genotype } \\
\text { and/or description }\end{array}$ & $\begin{array}{l}\text { Source or } \\
\text { reference }\end{array}$ \\
\hline \multicolumn{3}{|l|}{ R. etli strains } \\
\hline CFN 42 & Wild type & [29] \\
\hline CE3 & $\begin{array}{l}\text { Spontaneous } \mathrm{Sm}^{\mathrm{r}} \text { mutant of } R \text {, } \\
\text { etli CFN } 42 \mathrm{Nall}^{\mathrm{r}}\end{array}$ & {$[31]$} \\
\hline CMS310 & R. etli CE3 ots $A$ ch:: $\Omega \mathrm{Nal}^{r} \mathrm{Sm}^{\mathrm{r}} \mathrm{Spc}{ }^{r}$ & This study \\
\hline \multicolumn{3}{|l|}{ E. coli strain } \\
\hline $\mathrm{DH} 5 \mathrm{a}$ & $\begin{array}{l}\text { supE44D (lac) U169 } 980 d \\
\text { lacZDM15 hsdR17 recA1 } \\
\text { endA1 gyrA96 thi-1 relA1; } \\
\text { host for DNA manipulations }\end{array}$ & {$[35]$} \\
\hline \multicolumn{3}{|l|}{ Plasmids } \\
\hline $\operatorname{pSK}(-)$ & Cloning vector; $A p^{r}$ & Stratagene \\
\hline pUC19-301 & Cloning vector, $A p^{r}$ & $\begin{array}{l}\text { J. Onofre, } \\
\text { Personal } \\
\text { Communication }\end{array}$ \\
\hline $\mathrm{pHP} 45 \Omega$ & $\begin{array}{l}\text { pBR322 derivative carrying } \\
\text { the } \Omega \text { cassette; } A p^{r} S m^{r} S p^{r}\end{array}$ & {$[36]$} \\
\hline pRK600 & Helper plasmid; $\mathrm{Cm}^{\mathrm{r}}$ tra & {$[37]$} \\
\hline pJQ200-SK & Suicide vector; Gmrmobsac & {$[38]$} \\
\hline pMotsA1 & $\begin{array}{l}\text { 4.2-kb blunt fragment from } \\
\text { R. etli CE3 genome } \\
\text { (containing frk, otsAch, pgi) cloned } \\
\text { into pUC19301 in ECoRV; Apr }\end{array}$ & This study \\
\hline pMotsA4 & $\begin{array}{l}\text { 4,1-kb Bg/ll-Xbal fragment from } \\
\text { pMotsA1 cloned into pSK } \\
\text { in BamHI-Xbal; Ap }\end{array}$ & This study \\
\hline pMotsA5 & $\begin{array}{l}\text { pMotsA4 derivative } \\
\text { containing an Bg/ll recognition } \\
\text { site within otsAch; } A p^{r}\end{array}$ & This study \\
\hline pMotsA6 & 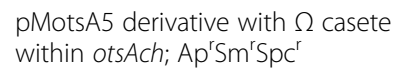 & This study \\
\hline pMotsA7 & $\begin{array}{l}\text { 6.1-kb Apal-Xbal fragment from } \\
\text { pMotsA6 (containing frk,otsAch, } \\
\text { pgi) cloned into } \\
\text { pJQ200-SK; Gm }{ }^{r} \mathrm{Sm}^{\mathrm{r}} \mathrm{Sp} \mathrm{c}^{\mathrm{r}}\end{array}$ & This study \\
\hline
\end{tabular}

medium was increased by the addition of 0.1 to $0.2 \mathrm{M}$ final concentration of $\mathrm{NaCl}$. $\mathrm{pH}$ was adjusted to 7.2 (for TY) or 5 (for $\mathrm{B}^{-}$). Solid media contained $2 \%$ of Bacto agar (Difco). E. coli cultures were incubated at $37^{\circ} \mathrm{C} . R$. etli cultures were incubated at $28^{\circ} \mathrm{C}$ or $35^{\circ} \mathrm{C}$ [29]. When used, filter sterilized antibiotics were added at the following final concentrations $\left(\mu \mathrm{g} \mathrm{ml}^{-1}\right)$ : ampicillin (ap), 150 for E. coli; chloramphenicol, 30 for E. coli; gentamicin (Gm), 20 for E. coli, 25 for R. etli; streptomycin (Sm) 20 for E. coli, 40 for R. etli; spectinomycin (Spc) 80-100 for $R$. etli and nalidixic acid 20 for $R$. etli. When appropriate, the following compounds were added to the media (final concentration): X-Gal (5-bromo-4-chloro-3indolyl- $\beta$-D-galactopyranoside, Sigma, $40 \mu \mathrm{g} / \mathrm{ml})$, IPTG (isopropyl- $\beta-D-1$-thiogalactopyranoside, Sigma, $25 \mu \mathrm{g} /$ $\mathrm{ml})$. Growth was monitored as the optical density of the culture at $600 \mathrm{~nm}\left(\mathrm{OD}_{600}\right)$ with a Perkin-Elmer Lambda $25 \mathrm{UV} / \mathrm{Vis}$ spectrophotometer.

\section{Tolerance to desiccation}

Aliquot volumes $(1 \mathrm{ml})$ of $\mathrm{B}^{-}$medium cultures in early stationary phase were harvested by centrifugation. Cell pellets were washed with the same medium without any carbon source, centrifuged for $5 \mathrm{~min}$ at $13000 \mathrm{rpm}$ and, after removing the supernatant, vacuum dried. Two variations of the protocol described by Manzanera et al. [39] were used. In a first step, two replicates of all samples were dried by vacuum in a Memmert V0200 vacuum oven at $20^{\circ} \mathrm{C}$ and 313 mbar for $20 \mathrm{~h}$. After that, for each sample, one replica was taken out from the oven, sealed and stored at $28^{\circ} \mathrm{C}$, and the other was subjected to a further step under vacuum consisting on a temperature ramping of $2^{\circ} \mathrm{C} / \mathrm{min}$ with a 15 -min pause after every increase of $2^{\circ} \mathrm{C}$, up to a maximum temperature of $30^{\circ} \mathrm{C}$, followed by storage at $28^{\circ} \mathrm{C}$. For assessment of viability, after variable time periods, dried samples were resuspended in $1 \mathrm{ml}$ of TY complex medium, and serial dilutions were plated on TY plates, incubated at $28^{\circ} \mathrm{C}$, and counted to determine CFU. Viability was measured before (taken as $100 \%$ survival) and just after drying, and at 4 days, 1, 2, and 3 weeks storage, and expressed as percentage of viable cells.

\section{Extraction and determination of intracellular solutes by ${ }^{13} \mathrm{C}$-NMR spectroscopy}

R. etli wild-type and otsA mutant strain (CMS310) were grown in $\mathrm{B}^{-}$medium with $0.2 \mathrm{M} \mathrm{NaCl}$ at $28^{\circ} \mathrm{C}$ until early-stationary phase. Cells were collected by centrifugation and washed with the same medium without any carbon source. Cell pellet was resuspended in $10 \mathrm{ml}$ of extraction mixture (methanol:chloroform:water; 10:5:4) and extracted by gently shaking for $30 \mathrm{~min}$ at $37^{\circ} \mathrm{C}$. Cell debris was removed by centrifugation, and supernatants were extracted once with chloroform:water (1:1) and 
freeze-dried. The solids were dissolved in $\mathrm{D}_{2} \mathrm{O}(0.6 \mathrm{ml})$. ${ }^{13} \mathrm{C}$-NMR spectra were recorded at $25^{\circ} \mathrm{C}$ on a Brucker AV500 spectrometer at $125 \mathrm{MHz}$. The chemical shifts are reported in $\mathrm{ppm}$ on the $\delta$ scale relative to tetramethylsilane. Signals were assigned by comparison with previously published chemical shift values [6] and compared with ${ }^{13} \mathrm{C}$-NMR of pure compounds.

\section{Extraction and determination of intracellular trehalose content}

Trehalose determination was performed basically as described by Blazquez et al. [40] by the following procedure. For free-living cells, pellets from $15 \mathrm{ml}$ of early stationary phase cultures in $\mathrm{B}^{-}$medium were washed with isotonic carbon-free medium and resuspended in $1 \mathrm{ml}$ of the same medium. Cells were lysed by $30 \mathrm{~min}$ of incubation at $95^{\circ} \mathrm{C}$ and, after centrifugation, the supernatant was used to determine the trehalose content in a total volume reaction of $200 \mu \mathrm{l}$ containing $100 \mu \mathrm{l}$ of the supernatant, $90 \mu \mathrm{l}$ of $25 \mathrm{mM}$ sodium acetate buffer ( $\mathrm{pH}$ 5.6) and $0.02 \mathrm{U}$ of trehalase (Sigma). For each sample, endogenous glucose was monitored by performing a parallel reaction in which trehalase was substituted by water. After overnight incubation at $37^{\circ} \mathrm{C}$, the glucose released by trehalose hydrolysis was determined by adding $150 \mu$ lof the previous reaction to $150 \mu \mathrm{l}$ of a mixture of $0.66 \mathrm{mg} \mathrm{ml}^{-1}$ Aspergillus niger glucose oxidase (Sigma), $0.25 \mathrm{mg} \mathrm{ml}^{-1}$ horseradish peroxidase in $0.5 \mathrm{M}$ phosphate buffer, $\mathrm{pH} 6.0$ (Sigma), and $50 \mu \mathrm{l}$ of $2.33 \mathrm{mg} \mathrm{ml}^{-1} \mathrm{o}$-toluidine (Panreac). After $30 \mathrm{~min}$ of incubation at $37^{\circ} \mathrm{C}, 1.5 \mathrm{ml}$ of water was added to the samples and absorption was measured at $420 \mathrm{~nm}$ in a Perkin Elmer Lambda $25 \mathrm{UV} / \mathrm{Vis}$ spectrophotometer. Values were compared to those obtained from stock solutions of glucose

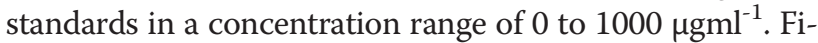
nally, trehalose content was calculated from the glucose content by performing a standard curve with commercial trehalose (Sigma) ranging from 1 to $5 \mathrm{mM}$. Trehalose concentration was expressed as $\mu \mathrm{mol} \mathrm{mg}$ protein $^{-1}$. Nodules were fractionated into bacteroids and nodule cytosol as described by Delgado et al. [41]. Trehalose content was determined colorimetrically as described above.

\section{Determination of protein content}

The same cultures were used for determination of both trehalose and protein content. $1 \mathrm{ml}$ aliquots were taken at early stationary phase and cell protein content was determined in triplicate by using a bicinchoninic acid (BCA) proteinassay kit (Pierce) as described by García-Estepa et al. [42].

\section{Methods for nucleic acid manipulation and construction of a $R$. etli otsA mutant}

Plasmid DNA was isolated from $E$. coli with a Wizard Plus SV miniprep kit (Promega), and genomic DNA was isolated with a SpinClean Genomic DNA Purification kit (Mbiotech). Restriction enzyme digestion and ligation were performed as recommended by the manufacturers (Amersham-Pharmacia Biotech and Fermentas). DNA sequencing was performed by Newbiotechnic (Seville, Spain). To generate the $R$. etli CE3 otsAch mutant CMS310 (otsAch:: $\Omega$ ), a 4.119-bp fragment from the $R$. etli genome containing 394-bp of the adjacent gene frk, otsAch and 1.488-bp of the pgi gene, was amplified with $P f u$ Turbo DNA polymerase (Stratagene) by using two synthetic oligonucleotides (ots $A^{\mathrm{R}}$-FW: 5'-AAGACGGCTGTGAACGACGAG-3' and ots $A^{\mathrm{R}}$-RV: 5'-CAAATCCGACATCGTCAAATTCTC-3'). The resulting PCR fragment was cloned into pUC19-301 digested with EcoRV to obtain the plasmid pMOtsA1. This plasmid was digested with $B g l \mathrm{II}-X b a \mathrm{I}$, to remove the $4.2-\mathrm{kb}$ fragment containing the ots $A$ region which was cloned in pSKbluescript previously digested with BamHI-XbaI to obtain the plasmid pMotsA4. Subsequently, a BglII recognition site was generated in otsAch gene sequence, using the PCR-based QuickChange Site Directed Mutagenesis Kit (Stratagene) and the primers: ots $A^{\mathrm{R}}$ BglII FW (5'-GAAGAGAGGGCATTGGCGAAGATCT CGGCAACGGATTGTTCGATTC-3'), and ots ${ }^{\overline{\mathrm{R}}}$-BglII RV (5'-GAATCGAACAATCCGTTGCCGAGATCTTCGCCA ATGCCCTCTCTTC-3'), that were modified (residues underlined) to generate the corresponding restriction site (in bold), to obtain the plasmid pMotsA5. To interrupt the ots $A$ gene, the resulting plasmid was linearized with the enzyme BglII and ligated to a 2-kb BamHI fragment obtained from $\mathrm{pHP} 45-\Omega$ plasmid [38], containing the $\Omega$ interposon for insertional mutagenesis $\left(\mathrm{Sm}^{\mathrm{r}}\right)$. The resulting plasmid was designated pMotsA6. To recombine the ots $A$ mutation into the $R$. etli chromosome, a 6.1-kb ApaI-XbaI fragment from pMotsA6 was cloned into the suicide vector pJQ200SK $\left(\mathrm{Gm}^{\mathrm{r}}\right)$ [38] to obtain plasmid pMotsA7, which was mobilized into the $R$. etli CE3 by triparental mating. Mutant strains resulting from a double homologous recombination event were identified as $\mathrm{Spc}^{\mathrm{r}} \mathrm{Gm}^{\mathrm{s}}$ colonies on TY plates containing $10 \%$ sucrose. One of these colonies was purified for further analysis and was designated CMS310 (otsAch). Insertion of the omega cassette in CMS310 was confirmed by PCR and sequencing.

\section{Conjugal transfer of plasmids}

Plasmids were transferred from E. coli to $R$. etli by triparental mating on TY medium, using pRK600 as a helper plasmid [37], as described by Vargas et al. [43] but with a 1:2:1:(donor:receptor:helper) ratio.

\section{Sequence and phylogenetic analyses}

The sequence of the $R$. etli CFN 42 genome is available at NCBI microbial genome database (http://www.ncbi.nlm. nih.gov/genomes/lproks.cgi; Ac $\mathrm{N}^{\circ}$ : NC_007761), and at 
http://www.ccg.unam.mx/retlidb/. Sequence data were analyzed using BLAST (NCBI http://ncbi.nlm.nih.gov/ BLAST). ORF assignments of the metabolic pathways more relevant for this work was performed by comparing the information available at the Kyoto Encyclopedia of Genes and Genomes (KEGG) [44] and MetaCyc [45]. Codon preference was analysed at the Kasuza Codon Use Database (http://www.kazusa.or.jp/codon/). Phylogenetic and molecular evolutionary analyses were conducted using MEGA version 5 [46]. Sequences were aligned with ClustalW (1.6) using a BLOSUM62 matrix, and manually edited. The phylogenetic tree was inferred using the Neighbor-Joining method [47], and the evolutionary distances were computed using the Poisson correction method. The rate variation among sites was modelled with a gamma distribution (shape parameter $=1$ ) and all positions containing gaps and missing data were eliminated only in pairwise sequence comparisons. The robustness of the tree branches was assessed by performing bootstrap analysis of the Neighbour-Joining data based on 1000 resamplings [48].

\section{Plant inoculation, growth conditions, and drought treatment}

Seeds of Phaseolus vulgaris, var. Negro jamapa were surface sterilized in $96 \%(\mathrm{v} / \mathrm{v})$ ethanol for $30 \mathrm{~s}$, followed by $5 \%$ sodium hypochlorite for $5 \mathrm{~min}$ and then thoroughly washed five times with sterilized water [41]. Sterilized seeds were incubated two hours in sterile distilled water in darkness. The imbibed seeds were deposited on plates containing $1 \%$ water-agar, and let them to germinate at $30^{\circ}$ $\mathrm{C}$ during $60 \mathrm{~h}$. Three day after sowing, selected uniform seedlings were planted in sterile $2-\mathrm{kg}$ pots (4/pot) containing a mixture of vermiculite/sand $(1: 1 \mathrm{v} / \mathrm{v})$ as substrate. Each seedling was inoculated with $1 \mathrm{ml}$ of the strains culture of $R$. etli wild-type and otsA mutant strain (CMS310) containing $10^{8}$ cells $/ \mathrm{ml}$ at the log-phase of growth. Plants were grown in controlled environmental chambers (night/ day temperature $19 / 25^{\circ} \mathrm{C}$, photoperiod $16 / 8 \mathrm{~h}$, PPF $400 \mu \mathrm{mol} \mathrm{m} \mathrm{m}^{-2} \mathrm{~s}^{-1}$ and relative humidity 60 to $70 \%$ ) [49]. Plants were watered with $\mathrm{N}$-free mineral solution [50] and water alternately. When plants were three weeks old, they were randomly separated into two sets: control and drought stress. Drought stress was imposed by withholding water for 5 days (moderate drought) or for 10 days (severe drought). Control plants were supplied daily with nutrients solution to field capacity. Leaf water potential $\left(\Psi_{\mathrm{w}}\right)$ was measured in the first fully expanded leaf of common bean plants with C52 sample chambers connected to a HR-33 T psychrometer (Wescor. Inc., Logan UT, USA).

\section{Plant and nodule biomass, nitrogen content and nitrogen-fixation assays.}

Plant and nodule dry weight were determined after drying fresh plant material that was heated at $60^{\circ} \mathrm{C}$ for $48 \mathrm{~h}$.
Total nitrogen content per plant was determined by the Kjeldahl method [51]. Nitrogenase activity was analyzed by using the acetylene reduction activity (ARA) assay. A Hewlett-Packard model 5890 gas chromatograph (Agilent Technologies, S.L., Madrid) equipped with a flame ionization detector was operated with a molecular sieve $5 \mathrm{~A}$ (60 to $80 \mathrm{mesh})$ column $(180 \times 0.32 \mathrm{~cm}) . \mathrm{N}_{2}$ at $60 \mathrm{ml} \mathrm{min}{ }^{-1}$ served as a carrier gas. Oven, injector, and detector temperatures were 60,90 , and $110^{\circ} \mathrm{C}$, respectively. Nodules $(0.3 \mathrm{~g})$ were placed in $17-\mathrm{ml}$ tubes that were filled with $10 \%$ acetylene. Gas samples $(0.5 \mathrm{ml})$ were taken from the tubes for ethylene analyses after incubation for 10 and $20 \mathrm{~min}$. Concentration of ethylene in each sample was calculated from standards of pure ethylene.

\section{Leghemoglobin content}

Leghemoglobin content was measured by fluorimetry as previously described by La Rue and Child [52]. Nodules $(0.3 \mathrm{~g})$ were ground with $4 \mathrm{ml} \mathrm{Lb}$ extraction buffer $\left(\mathrm{Na}_{2} \mathrm{HPO}_{4} \cdot 2 \mathrm{H}_{2} \mathrm{O} \quad 40 \mathrm{mM} \quad(\mathrm{pH} \quad 7.4) ; \quad \mathrm{NaH}_{2} \mathrm{PO}_{4} \cdot \mathrm{H}_{2} \mathrm{O}\right.$ $10 \mathrm{mM}$ (pH 7.4); $\mathrm{K}_{3} \mathrm{Fe}(\mathrm{CN})_{6} 0.02 \% ; \mathrm{NaHCO}_{3} 0.1 \%$ ) supplemented with $0.1 \mathrm{~g}$ polyvinylpolypirrolidone (PVPP). The homogenate was centrifuged at $12000 \mathrm{rpm}$ at $4^{\circ} \mathrm{C}$ for $20 \mathrm{~min}$, to retain the supernatant. Clear supernatant $(50 \mu \mathrm{l})$ and saturated oxalic acid $(3 \mathrm{ml})$ were mixed in screwcapped tubes, which were sealed and autoclaved for $30 \mathrm{~min}$ at $120^{\circ} \mathrm{C}$ and then let to cool to room temperature. The fluorescence of the solutions was measured with a Shimadzu (Shimadzu Scientific Instruments, Kyoto, Japan) spectrophotofluorometer equipped with a mercury-xenon lamp and a RF-549 red-sensitive photomultiplier. The excitation wavelength was $405 \mathrm{~nm}$ and the emission monochromator setting was $650 \mathrm{~nm}$. The difference in fluorescence between heated and unheated samples was proportional to haem protein concentration.

\section{Results}

\section{Trehalose synthesis by R.etli is triggered mainly by salinity stress}

Heat stress induces accumulation of trehalose in yeasts [25] and bacteria such as E. coli [26] or Salmonella typhi serovar Typhimurium [27]. In rhizobia, including $R$. etli [10], trehalose synthesis has been shown to be stimulated by salinity, but its role against heat stress has not been yet tested. In this study, we compared the influence of salinity and high temperature on growth and trehalose accumulation in $R$. etli. For this purpose, $R$. etli wild-type strain was grown up to early stationary phase in $\mathrm{B}^{-}$minimal medium alone or with $0.2 \mathrm{M} \mathrm{NaCl}$, at $28^{\circ} \mathrm{C}$ and $35^{\circ} \mathrm{C}$, and trehalose content was determined colorimetrically as described in Materials and Methods. As shown in Figure 1, osmotic stress alone 


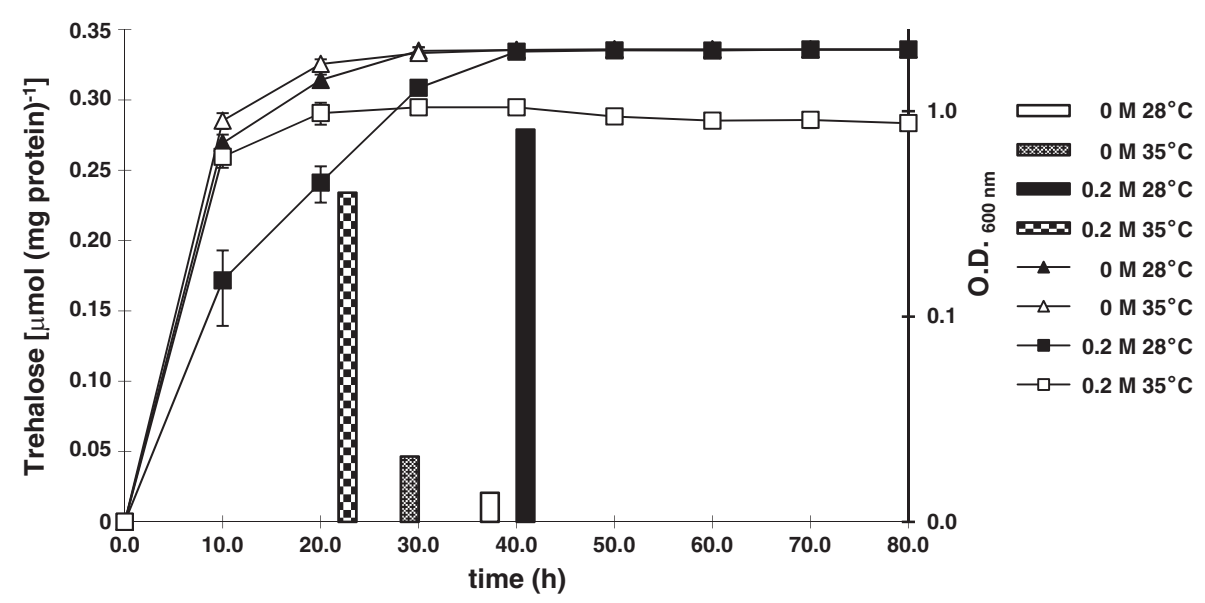

Figure 1 Growth and accumulation of trehalose by $R$. etli in response to high temperature and salinity stress. Cells were grown in mannitol minimal medium $\mathrm{B}^{-}$at $28^{\circ} \mathrm{C}$ and $35^{\circ} \mathrm{C}$, with 0.0 and $0.2 \mathrm{M} \mathrm{NaCl}$, up to early stationary phase. Trehalose content was measured colorimetrically as described in Materials and Methods. For each determination, a growth curve under the same condition used to measure trehalose accumulation is shown. Histograms representing trehalose accumulation are shown above the sampling time. The trehalose values are the mean of three replicas of each condition in two independent experiments \pm SD (standard deviation).

caused a delayed growth, but high temperature alone did not influence growth of $R$. etli. However, growth of cells subjected to both stresses was more impaired than that of cells grown under osmotic stress alone, showing an attenuated exponential phase, and reaching final $\mathrm{O}$. $D_{600}$ values below 0.9. As shown in Figure 1, under non stress conditions, trehalose levels in $R$. etli were below $0.025 \mu \mathrm{mol} / \mathrm{mg}$ protein. To determine trehalose content in response to high temperature stress, we compared the accumulation of trehalose at $28^{\circ} \mathrm{C}$ and $35^{\circ} \mathrm{C}$ in cells grown without $\mathrm{NaCl}$ added. Under these conditions, trehalose accumulation by $R$. etli cells increased by $2.2-$ fold, but trehalose levels remained very low. However, a pronounced response in trehalose accumulation was observed due to salinity stress at both temperatures. Thus, trehalose levels in cells grown in minimal medium with $0.2 \mathrm{M} \mathrm{NaCl}$ at $28^{\circ} \mathrm{C}$ and $35^{\circ} \mathrm{C}$ were 13.5 and 5.04- higher, respectively, than trehalose levels in cells grown in minimal medium without $\mathrm{NaCl}$ added. These data suggest that, although temperature stress alone induces some trehalose synthesis by $R$. etli, trehalose biosynthesis in this microorganism is mainly triggered by osmotic stress.

\section{Genomic analysis of trehalose metabolism in $R$. etli}

Trehalose synthesis and catabolism have proven to be relevant for the symbiotic performance of rhizobia $[5,10,21,22]$. To get an overview of the metabolism of trehalose in $R$. etli, we inspected its genome for genes involved in trehalose synthesis, transport and degradation. Genes for trehalose metabolism were scattered among the chromosome and plasmids a, c, e, and $\mathrm{f}$ (see Additional file 1: Table S1 and Additional file 2: Figure
S1A, for a complete description of gene annotation and gene clustering). As suggested by Suarez et al. [10] putative genes encoding the three so far known trehalose synthesis pathways in rhizobia (TreYZ, TreS and OtsAB) are present in $R$. etli. First, genes encoding trehalose synthesis from glucose polymers were found in plasmid p42e (treY), and the chromosome and plasmid p42f (two copies of treZ). Second, two genes encoding a putative trehalose synthase (TreS) were found in the chromosome and plasmid p42f. The product of the chromosomal putative treS gene presented similar length and significant sequence identity to known trehalose synthases from bacteria, but the product of the plasmid f-borne treS-like gene carried an additional domain of unknown function (DUF3459).Third, two genes were annotated as ots $A$, one located in the chromosome (otsAch) and one in plasmid p42a (ots $A a)$. Both products showed homology to trehalose 6-phosphate synthases from other rhizobia, but the identity was much higher for OtsAch. In addition, a gene annotated as otsB was located in plasmid c. As trehalose is synthesized by $R$. etli from mannitol (see Figure 1), we searched for genes involved in mannitol transport and conversion into glucose. The genome of $R$. etli does not encode a specific mannitol phosphotransferase, suggesting that mannitol does not use this system to enter the cell. Instead, we found smoEFGK (encoding a sorbitol/mannitol $\mathrm{ABC}$ transporter), $m t l K$ (encoding a mannitol 2-dehydrogenase that converts mannitol to fructose), and xylA (encoding a xylose isomerase that converts fructose to glucose. All these findings suggest that $R$. etli can convert mannitol into glucose via fructose. $R$. etli CE3 grown in minimal 
medium $\mathrm{B}^{-}$also accumulates glutamate (see below). Since $\mathrm{B}^{-}$does not contain ammonium, the most plausible route for glutamate biosynthesis from mannitol is through the enzyme glucosamine-6-phosphate synthase, which converts D-fructose-6-phosphate and L-glutamine into D-glucosamine-6-phosphate and L-glutamate. Two copies of the encoding gene $(\mathrm{g} \operatorname{lm} S)$ were found in $R$. etli chromosome (Additional file 1: Table S1, Figure 2). A previous study suggested that $R$. etli can degrade trehalose [53]. Therefore, we also looked for genes involved in uptake and degradation of trehalose. We did not find a trehalose phosphotransferase system (PTS) for the uptake of trehalose, but two putative $\mathrm{ABC}$ uptake systems homologous to those operating in S. meliloti $[22,23]$ were found that might be involved in the uptake of trehalose, sucrose, and/or maltose. These were encoded in plasmid p42f (ThuEFGK), and the chromosome (AglEFGK). Regarding trehalose degradation, neither E. coli treA- or treF- like genes for periplasmic or cytoplasmic trehalases, respectively, nor genes belonging to glycoside hydrolase family 15 trehalases [16,17], were found in the $R$. etli genome. However, orthologs to the $t h u A B$ genes, which encode the major pathway for trehalose catabolism in S. meliloti [21], were found in the chromosome and plasmid p42f. In addition, three copies of tre $C$, encoding putative trehalose-6-phosphate hydrolases, were identified in the chromosome. All three TreC proteins belonged to the family 13 of glycoside hydrolases [16], but they did not cluster together (see the phylogenetic tree in Additional file 2: Figure S1B). The metabolism of trehalose in $R$. etli inferred from its genome sequence is summarized in Figure 2.

\section{Phylogenetic analysis of the two R. etli trehalose-6- phosphate synthases}

As two copies of OtsA (OtsAch and OtsAa, Figure 3A) were encoded by the $R$. etli genome, we investigated their phylogenetic relationship. First we aligned the amino acid sequences of both $R$. etli OtsA proteins with the sequences of characterized trehalose-6-P- synthases, and compared motifs involved in enzyme activity. All residues corresponding to the active site determined in the best studied E. coli trehalose-6-P synthase [54] were conserved in $R$. etli OtsAch and OtsAa (data not shown). However, the identity between both proteins was only of $48 \%$, and the gene otsAa was flanked by putative insertion sequences in the $R$. etli genome. In addition, the otsAch copy and $R$. etli genome had a similar codon use, whereas the otsAa copy showed a different preference for Stop codon, and codons for amino acids as Ala, Arg, Gln, Ile,Leu, Phe, Ser, Thr, and Val. These findings suggested that ots $A a$ might have been

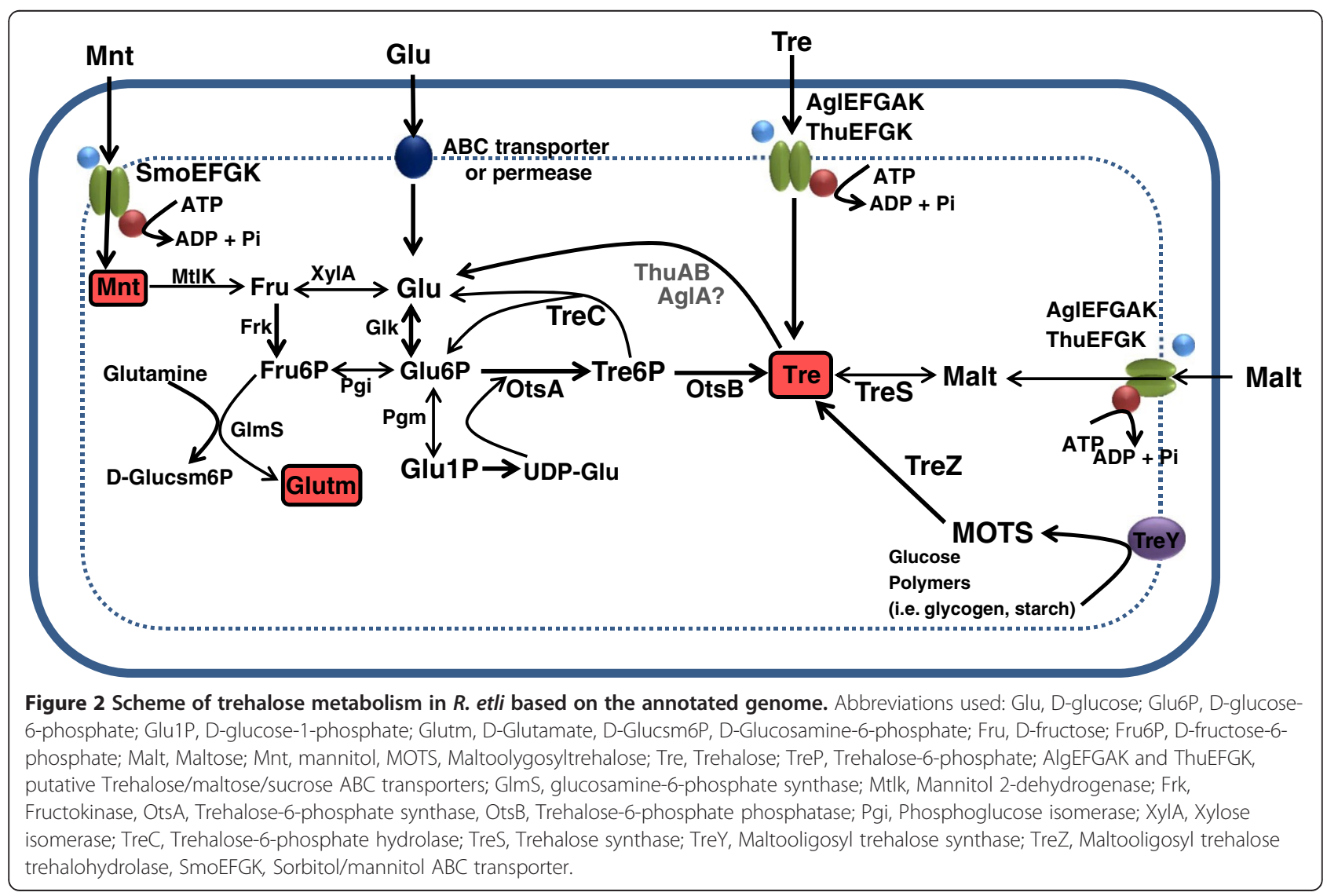


A

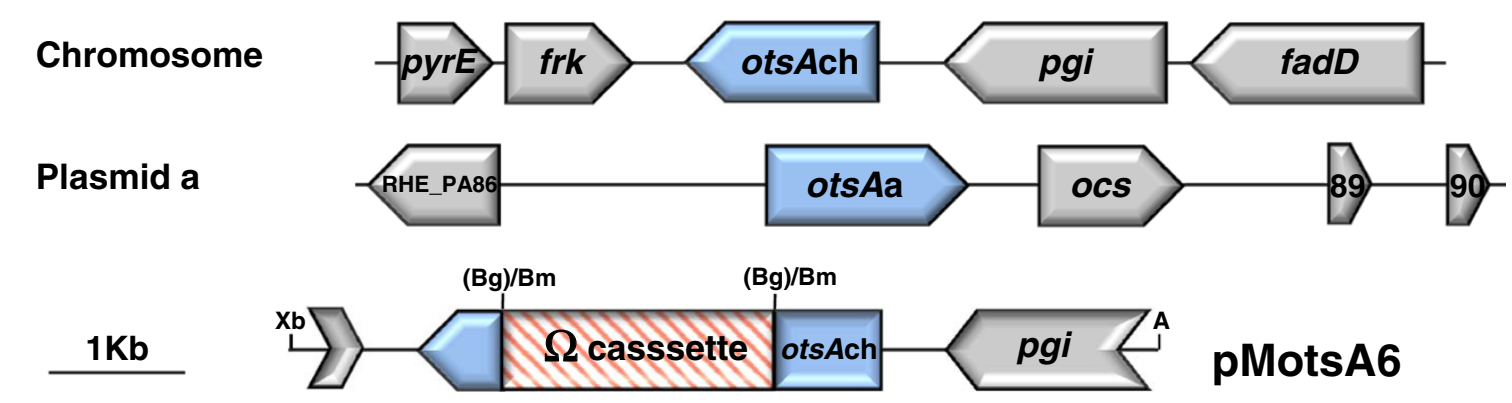

B

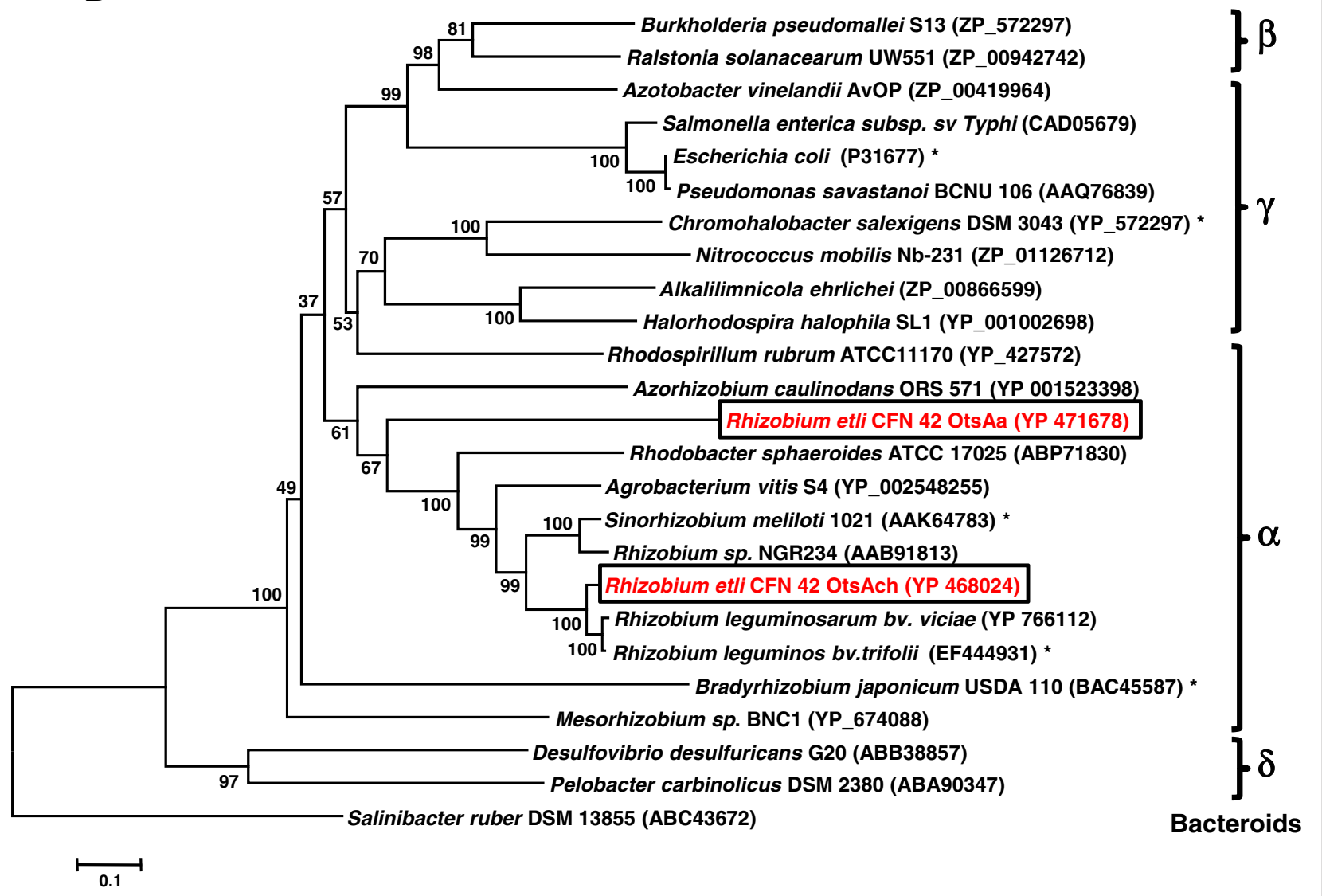

Figure 3 In silico analysis of the two trehalose-6-phosphate synthases (OtsA) encoded by the R. etli genome. (A) Genomic context of the otsAch (chromosomal) and otsAs (plasmid p42a) genes, and construction of an otsAch mutant. otsAch was inactivated by the insertion of a BamHI (Bm)-digested $\Omega$ cassette, which carried resistance genes for streptomycin/spectinomycin, into its unique site Bglll (Bg), giving the plasmid pMotsA6 (see text for details). (B) Neighbor-joining tree based on OtsA proteins from $\alpha-, \beta-, \gamma$ and $\delta$-proteobacteria. The tree is drawn to scale, with branch lengths in the same units as those of the evolutionary distances used to infer the phylogenetic tree. The Bacteroides/Chlorobi representative $S$. ruber was used as outgroup. The evolutionary distances were computed using the Poisson correction method and are in the units of the number of amino acid substitutions per site. The rate variation among sites was modeled with a gamma distribution (shape parameter $=1$ ). All positions containing gaps and missing data were eliminated from the dataset (complete deletion option). Bootstrap probabilities (as percentage) were determined from 1000 resamplings.

acquired by horizontal transfer. To check this hypothesis, we constructed a phylogenetic tree with sequences of proteobacterial OtsA proteins available in the data bases, including OtsAs from $R$. etli and other rhizobia like $R$. leguminosarum bv. trifolii [7], S.meliloti [5], and B. japonicum [2]. As shown in Figure 3B, the resulting phylogenetic tree showed four separated branches, with a generally homogeneous distribution of phylogenetic 
groups. The first branch was formed by OtsA proteins from $\beta$ - and $\gamma$-proteobacteria, including OtsA from $E$. coli and Salmonella enterica. The second cluster was mainly composed of OtsA proteins from $\gamma$-proteobacteria, including some halophilic representatives such as C. salexigens and Halorhodospira halophila. The third branch grouped OtsAs from $\alpha$-proteobacteria, including the two $R$. etli OtsA proteins. Whereas $R$. etli OtsAch grouped with OtsAs from R. leguminosarum, S. meliloti, Rhizobium sp. NGR234 and Agrobacterium vitis, $R$. etli OtsAa constituted a separated sub-group within the $\alpha$ proteobacterial branch. The fourth branch was composed by OtsA proteins from $\delta$-protobacteria. Some incongruences were found, as B. japonicum and Mesorhizobium proteins did not clustered with OtsA proteins from other rhizobia. In summary, this phylogenetic analysis supports the hypothesis that ots $A a$ was transferred to $R$. etli or its ancestor from a related $\alpha$-proteobacteria, which did not belong to the Rhizobium/Agrobacterium group.

\section{Inactivation of $R$. etli otsAch totally suppresses trehalose synthesis from mannitol}

From the above phylogenetic analysis, otsAch was chosen as the most promising candidate to encode a functional trehalose-6-P-synthase. To check this, the corresponding mutant (strain CMS310) was constructed by insertion of an omega cassette within otsAch (Figure 3A), followed by double recombination in the chromosome of the wild-type strain. Then, we used natural abundance ${ }^{13} \mathrm{C}-\mathrm{NMR}$ to determine the compatible solute pool of wild type and otsAch cells grown at $28^{\circ} \mathrm{C}$ in $0.2 \mathrm{M} \mathrm{NaCl} \mathrm{B}$ medium up to early-stationary phase. As shown in Figure $4 \mathrm{~A}$, the ${ }^{13} \mathrm{C}$-NMR spectrum of $R$. etli wild-type strain contained three sets of chemical shifts, which were assigned to trehalose $(61.2,70.4,71.7$, $72.8,73.2$ and $93.9 \mathrm{ppm})$, mannitol $(63.9,70.0$ and $71.6 \mathrm{ppm})$ and glutamate $(27.6,34.2,55.4,175.2$ and $181.9 \mathrm{ppm})$. Although ${ }^{13} \mathrm{C}-\mathrm{NMR}$ is only a semiquantitative technique, it was evident that trehalose levels were much higher than those of mannitol and glutamate, suggesting that trehalose is the major compatible solute of $R$. etli under these conditions. Mannitol was absent when glucose was used as a sole carbon source (data not shown), indicating that it was accumulated by $R$. etli after its uptake from the external medium. Chemical shifts corresponding to trehalose were not present in the spectrum of the $R$. etli otsAch strain, where only signals corresponding to mannitol were detected (Figure 4B). From these results, we conclude that the product encoded by otsAch is involved in trehalose synthesis in $R$. etli. Moreover, at least under the conditions tested, the otsAa copy does not seem to be functional.

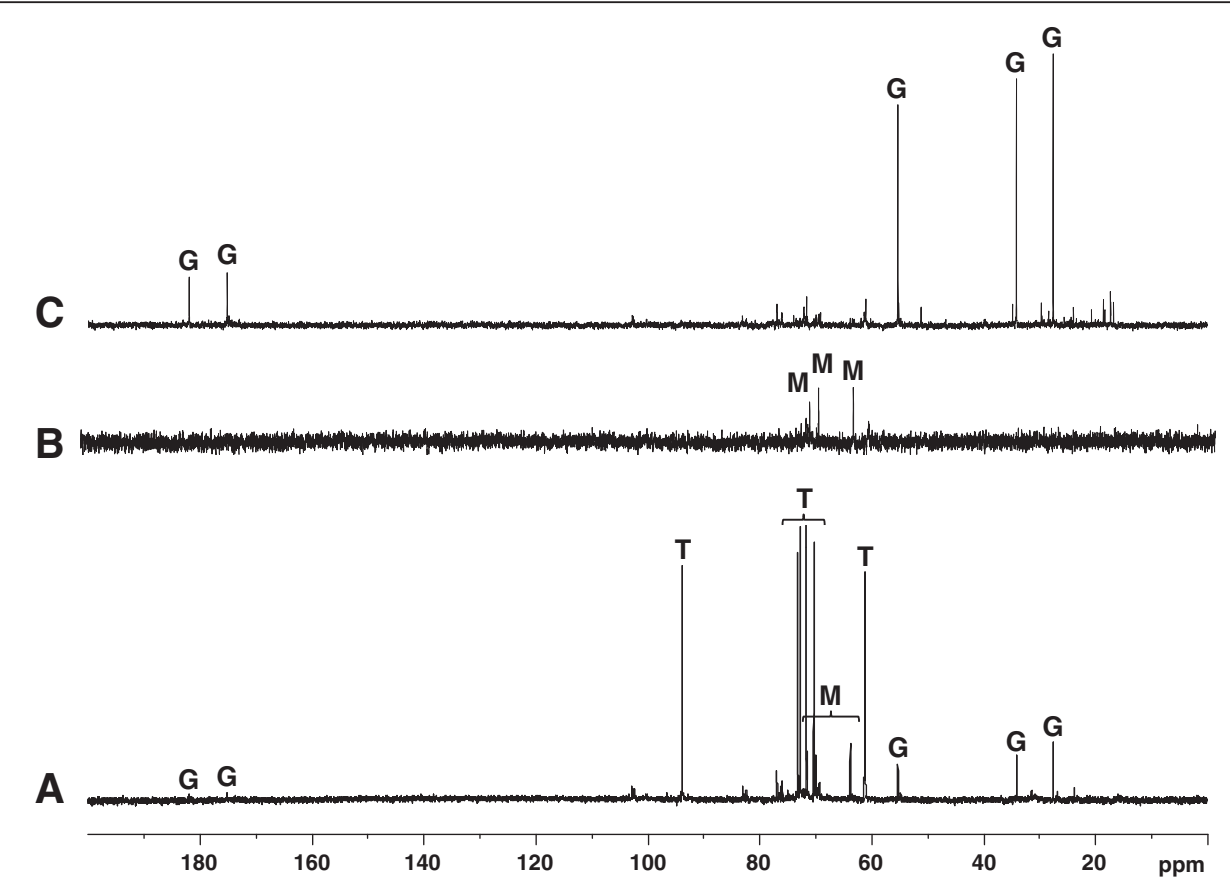

Figure 4 Natural abundance ${ }^{13} \mathrm{C}$-NMR spectrum of major cytosolic solutes accumulated by $R$. etli wild-type and otsAch strains. Wild-type (A) and otsAch $(\mathbf{B}, \mathbf{C})$ cells were grown at $28^{\circ} \mathrm{C}$ in $\mathrm{B}^{-}$minimal medium with $0.2 \mathrm{M} \mathrm{NaCl}$. Cells were extracted as described in Materials and Methods. For the otsAch strain, cells were collected at the entrance of the first (B) and second (C) stationary phase of growth. The major solutes were trehalose $(T)$, glutamate $(G)$ and mannitol $(M)$. 
Trehalose synthesis mediated by otsAch is essential for thermoprotection of $R$. etli

We investigated the effect of a mutation in otsAch on $R$. etli heat tolerance. For this purpose, we compared the growth of wild-type and otsAch strains in minimal medium $\mathrm{B}^{-}$under different combinations of osmotic $(0.0 \mathrm{M}$ to $0.2 \mathrm{M})$ and heat $\left(28^{\circ} \mathrm{C}\right.$ or $\left.35^{\circ} \mathrm{C}\right)$ stresses. As previously described (see Figure 1), at optimal temperature $\left(28^{\circ} \mathrm{C}\right)$, the wild-type strain grew optimally without $\mathrm{NaCl}$ added. At higher salinities (0.1 to $0.2 \mathrm{M}$ $\mathrm{NaCl}$ ), wild-type cells showed a delayed growth, but eventually they reached a stationary phase with absorbance values comparable to those of cultures without $\mathrm{NaCl}$ (Figure 5A).

Interestingly, otsAch cells grown at $28^{\circ} \mathrm{C}$ with mannitol showed a biphasic pattern, which was independent of the $\mathrm{NaCl}$ concentration, although cells exposed to osmotic stress were more affected than cells grown without $\mathrm{NaCl}$. The first stage consisted of an attenuated exponential phase of $20 \mathrm{~h}$ (if compared with that of the wild type) followed by $30 \mathrm{~h}$ of arrested growth with $\mathrm{OD}_{600}$ values of around 0.5 units. In the second one, growth was restarted, showing a second exponential phase during $40 \mathrm{~h}$, followed by a second stationary phase with absorbance values comparable to those of the wild type strain (Figure 5A). As in otsAch cells collected at the beginning of the first stationary phase (see Figure 4B), trehalose was absent from extracts prepared from samples harvested at the entrance of this second stationary phase. Instead, they contained large amounts of glutamate (Figure $4 \mathrm{C}$ ). However, when glucose and trehalose were used as the sole carbon source, this biphasic pattern of growth was not observed. Growth of the otsAch strain with both carbon sources was delayed with respect to the wild-type strain, even in the absence of osmotic stress (see Additional file 3: Figure S2).

At $35^{\circ} \mathrm{C}, R$. etli wild-type strain was able to grow well in $\mathrm{B}^{-}$medium with $\mathrm{NaCl}$ concentrations ranging from 0 to $0.15 \mathrm{M}$. As described above (see Figure 1), growth of the wild type was impaired at $35^{\circ} \mathrm{C}$ with $0.2 \mathrm{M} \mathrm{NaCl}$, showing absorbance values not exceeding 1.0 unit of $\mathrm{OD}_{600}$ (Figure $5 \mathrm{~B}$ ). At this temperature, growth of the ots $A$ mutant was severely affected, regardless of the salinity of the culture medium, with cultures showing $\mathrm{OD}_{600}$ around $0.5 \mathrm{OD}$ units. The above data suggest that trehalose is essential for growth of $R$. etli at high temperature.

\section{Osmotically induced trehalose synthesis improves desiccation tolerance in $R$. etli}

Involvement of trehalose in desiccation tolerance in rhizobia has been firmly established in R. leguminosarum bv. trifolii [7]. On the other hand, in S. meliloti [55] or rhizobia nodulating Acacia [56], desiccation tolerance was stimulated by osmotic and/or temperature pretreatment. To check the influence of trehalose on desiccation tolerance of $R$. etli, wild type and otsAch strains were grown at $28^{\circ} \mathrm{C}$ in minimal medium $\mathrm{B}^{-}$alone or additioned with $0.2 \mathrm{M} \mathrm{NaCl}$, and harvested at early stationary phase. For cell drying, we used two variants of the protocol described by Manzanera et al. for $E$. coli [39], a drying process (induced by vacuum at $30^{\circ} \mathrm{C}$ ) or a drying + high temperature process (including a second step with a controlled increase of temperature from 20 to $30^{\circ} \mathrm{C}$ under vacuum).

In the absence of osmotic stress, both wild type and otsAch strains showed survival levels under $0.01 \%$, regardless of the drying protocol (data not shown). In
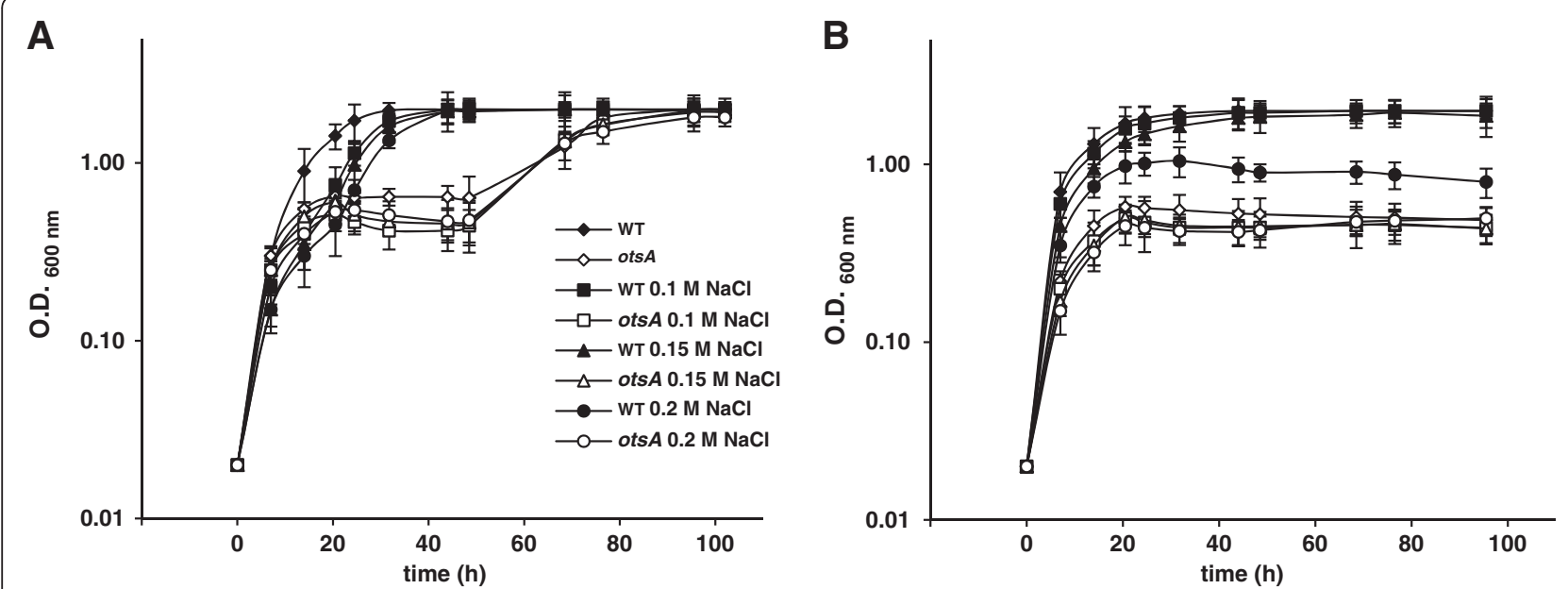

Figure $\mathbf{5}$ Contribution of trehalose to salinity and heat tolerance of $\boldsymbol{R}$. etli. Cells of R. etli wild-type (black markers) and otsAch mutant (white markers) were grown in minimal medium $\mathrm{B}^{-}$with 0.0 or $0.2 \mathrm{M} \mathrm{NaCl}$ at $28^{\circ} \mathrm{C}(\mathbf{A})$ or $35^{\circ} \mathrm{C}(\mathbf{B})$. $10 \mathrm{gl}^{-1}$ mannitol was used as the sole carbon source. Values shown are the mean of two replicas of each condition in three independent experiments \pm SD (standard deviation). 
contrast, wild type cells osmotically pre-conditioned by the presence of $0.2 \mathrm{M} \mathrm{NaCl}$ showed ca. 35\% survival levels after drying, although viability after 4 days storage dropped down to $1.4 \%$ (Figure 6). Compared to the drying treatment, the drying + high temperature protocol did not enhance wild type cell survival (Figure 6). The same drying experiments were performed with trehalose-deficient (otsAch) cells harvested at early stationary phase. Regardless of the protocol used, the otsAch strain showed ca 3-fold lower survival levels than the wild type strain after the drying process, and a null viability after 4 days storage. These findings suggested (i) a beneficial effect of osmotic stress in $R$. etli tolerance to desiccation, and (ii) a role of trehalose on desiccation tolerance in $R$. etli.

\section{Symbiotic phenotype of the $R$. etli otsAch mutant}

To analyze if the otsAch mutation modifies the capacity of $R$. etli to fix nitrogen in symbiosis, common bean plants were inoculated with $R$. etli wild-type and the otsAch strain. After inoculation, plants were grown under optimal (control plants) or water deficit conditions and were evaluated for nodulation, plant dry weight, total nitrogen content, nitrogenase activity, and leghaemoglobin content of the nodules. Plant water status during the different treatments was monitored by measuring water potential $\left(\Psi_{\mathrm{w}}\right)$ of the first fully expanded leaf. Water potential in plants subjected to drought stress by holding irrigation for 5 days reached values of about $-1 \pm 0.25 \mathrm{MPa}$ (moderate drought). When irrigation was stop for 10 days, leaf $\Psi_{\mathrm{w}}$ reached values of about $-2 \pm 0.3 \mathrm{MPa}$ (severe drought). The control plants maintained a leaf $\Psi_{\mathrm{w}}$ of $-1 \pm 0.4 \mathrm{MPa}$. The effect of either moderate or severe drought stress in leaf $\Psi_{\mathrm{w}}$ of plants inoculated with the otsAch mutant was similar to that of plants inoculated with the wild type (data not shown).

Independently of the plant treatment, no significant differences were observed in nodulation, plant growth parameters, and nitrogen fixation parameters among plants inoculated with any of the strains (Table 2). A moderate drought did not affect nodules number $(\mathrm{NN})$, nodule dry weight (NDW), plant dry weight (PDW), and total nitrogen content (TN) of plants inoculated with either the wild-type or the otsAch strain (Table 2). Specific nitrogenase activity expressed as acetylene reduction activity (ARA) and leghaemoglobin (Lb) content of the nodules as an estimation of nodule functionality were also measured. Regardless of the plant treatment, inoculation of plants with the otsAch mutant did not affect significantly ARA or Lb content compared to those plants inoculated with the wild-type strain (Table 2).

As shown in Table 2, NN and NDW per plant was negatively affected by a severe drought since a decrease of about $45 \%$ and $53 \%$ in those parameters was observed in plants inoculated with the wild-type strain compared to control plants. A similar decrease of $\mathrm{NN}(43 \%)$ and NDW (49\%) was observed in plants subjected to a severe stress and inoculated with the otsAch mutant compared to control plants (Table 2). After a severe drought, a $53 \%$ and $49 \%$ reduction of PDW was observed in plants inoculated with the wild-type or the otsAch mutant, respectively. Plants inoculated with any of the strains and subjected to severe drought showed a similar reduction of about $30 \%$ in TN compared to control plants (Table 2). Plants inoculated with the wild-type strain and

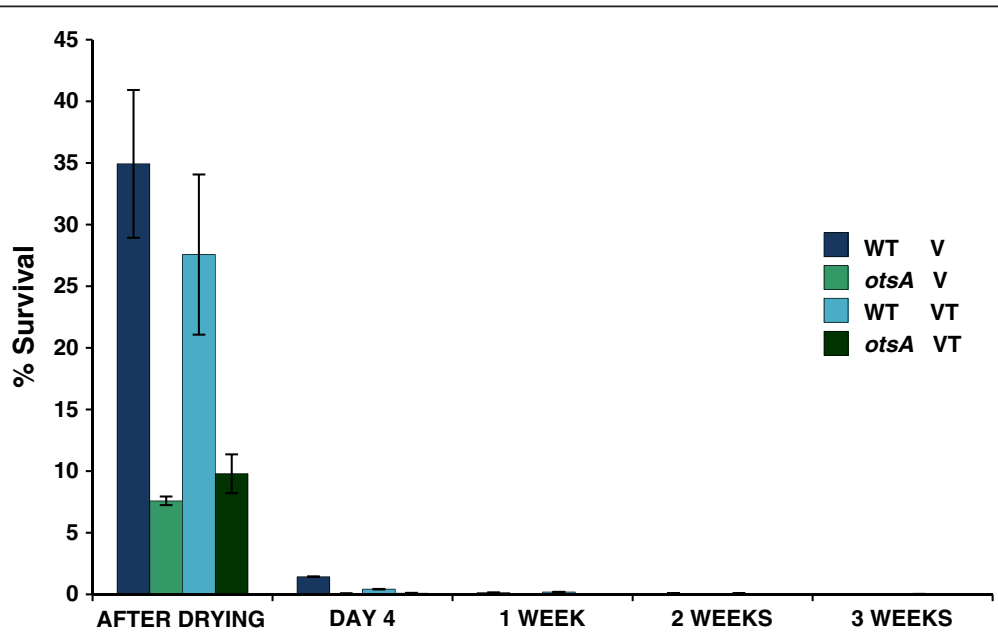

Figure 6 Survival of $R$. etli strains after vacuum-drying and subsequent storage at $28^{\circ} \mathrm{C}$. $R$. etli wild-type and otsAch mutant were cultured at $28^{\circ} \mathrm{C}$ in minimal medium $B^{-}$with $0.2 \mathrm{M} \mathrm{NaCl}$ until they reached early stationary phase: Desiccation was performed as described in Methods, using vacuum or vacuum + temperature conditions. After drying, samples were sealed and stored at $28^{\circ} \mathrm{C}$. Viability was measured before (taken as $100 \%$ survival), just after drying, and after 4 days, 1, 2 and 3 weeks storage, and expressed as percentage of viable cells. Error bars indicate standard deviations. 
Table 2 Symbiotic phenotype of the otsAch mutant

\begin{tabular}{|c|c|c|c|c|c|c|c|c|c|c|c|c|c|c|c|c|c|}
\hline \multirow{2}{*}{ Strain } & \multirow{2}{*}{ Treatment } & \multicolumn{8}{|c|}{ Moderate drought } & \multicolumn{8}{|c|}{ Severe drought } \\
\hline & & NN & NDW & PDW & TN & ARA & Lb & Tre (B) & Tre (C) & NN & NDW & PDW & TN & ARA & Lb & Tre (B) & Tre (C) \\
\hline \multirow[t]{2}{*}{ Wild-type } & Control & $48 \pm 6 a$ & $23 \pm 3 a$ & $0.31 \pm 0.02 a$ & $4.5 \pm 0.3$ & $24 \pm 1 a$ & $33 \pm 1 a$ & $1.17 \pm 0.32 a$ & ND & $56 \pm 4 a$ & $35 \pm 3 a$ & $0.51 \pm 0.03 a$ & $12 \pm 0.4 a$ & $22 \pm 0.6 a$ & $37 \pm 2 a$ & $2.12 \pm 0.43 b$ & ND \\
\hline & Stress & $45 \pm 4 a$ & $22 \pm 3 a$ & $0.34 \pm 0.02 a$ & $5.0 \pm 0.2$ & $22 \pm 2 a$ & $32 \pm 1 a$ & $1.24 \pm 0.20 \mathrm{a}$ & ND & $31 \pm 3 b$ & $16 \pm 1 b$ & $0.34 \pm 0.03 b$ & $5.3 \pm 0.1 b$ & $14 \pm 0.7 b$ & $24 \pm 1 b$ & $2.37 \pm 0.39 b$ & ND \\
\hline \multirow[t]{2}{*}{ otsAch } & Control & $48 \pm 5 a$ & $24 \pm 3 a$ & $0.37 \pm 0.03 a$ & $5.5 \pm 0.4$ & $27 \pm 3 a$ & $35 \pm 3 a$ & $1.15 \pm 0.29 a$ & ND & $61 \pm 4 a$ & $42 \pm 5 a$ & $0.52 \pm 0.03 a$ & $12.5 \pm 0.5 a$ & $27 \pm 1.2 \mathrm{a}$ & $41 \pm 4 a$ & $1.90 \pm 0.32 b$ & ND \\
\hline & Stress & $46 \pm 5 a$ & $25 \pm 5 a$ & $0.35 \pm 0.05 a$ & $5.3 \pm 0.3$ & $24 \pm 1 a$ & $35 \pm 3 a$ & $1.25 \pm 0.30 a$ & ND & $35 \pm 5 b$ & $19 \pm 3 b$ & $0.37 \pm 0.03 b$ & $5.5 \pm 0.3 b$ & $16 \pm 1.5 b$ & $25 \pm 1 b$ & $2.08 \pm 0.37 b$ & ND \\
\hline
\end{tabular}

Nodules number (NN), nodule dry weight [NDW, $\left.\left(\mathrm{mg} \mathrm{plant}^{-1}\right)\right]$, plant dry weight [PDW, (g plant $\left.{ }^{-1}\right)$ ], total nitrogen content [TN, $\left(\mathrm{mg} \mathrm{plant}^{-1}\right)$, acetylene reduction activity [ARA, $\left(\mu \mathrm{mol} \mathrm{C}_{2} \mathrm{H}_{4} \mathrm{~h}^{-1} \mathrm{~g}^{-1} \mathrm{NDW}\right)$, leghaemoglobin

[Lb, ( $\left.\left.\mathrm{mg} \mathrm{Lb} \mathrm{g}^{-1} \mathrm{NDW}\right)\right]$, and trehalose (Tre) in bacteroids (B) and nodule cytosol (C) [ $\mu \mathrm{mol} \mathrm{gDW}^{-1}$ ] content in nodules and plants subjected or not (control) to moderate or severe drought conditions. Values in a column

followed by the same lower-case letter are not significantly different as determined by the Tukey HSD test at $P \leq 0.05(\mathrm{n}=9)$.

ND. Not detected. 
subjected to severe drought showed an inhibition of ARA of about $36 \%$ compared to control plants. This activity was similarly dropped in nodules produced by the otsAch mutant under severe drought (41\% compared to control plants) (Table 2). A severe drought provoked a significant decline in Lb content of about 35\% in plants inoculated with the wild-type strain compared to control plants Likewise, this parameter was also reduced of about 39\% in plants inoculated with the otsAch mutant and subjected to a severe drought (Table 2). Finally, trehalose content in bacteroids of the wild type and otsAch strains was similar, regardless of the treatment, suggesting that under symbiotic conditions (i.e. with other trehalose precursors available) other trehalose synthesis genes (i.e. TreS or TreYZ) may be operating. Trehalose was not detected in the cytosol of nodules induced by either the wild type or the otsAch strain under any condition tested, suggesting that trehalose in the $R$. etli-induced nodules is synthesized only by the microsymbiont.

\section{Discussion}

Trehalose in rhizobia is a key compound for signaling plant growth, yield and adaptation to abiotic stress, and its manipulation has a major agronomical impact on leguminous plant. In this work we reconstructed trehalose metabolism in $R$. etli, and investigated the role of trehalose in the response to high temperature and desiccation stress, as well as symbiotic performance. By using ${ }^{13} \mathrm{C}$ NMR, we showed that besides trehalose as the major compatible solute, $R$. etli CE3 also amasses glutamate. In addition, it can accumulate mannitol if present in the external medium. The same compatible solute profile was recently reported for the strain $R$. etli $12 \mathrm{a} 3$, isolated from $P$. vulgaris nodules in Tunisian fields [6].

Two successive genome-based metabolic reconstructions of $R$. etli have been reported, covering in total 405 reactions and 450 (but not trehalose-related) genes $[57,58]$. In this study, we reconstructed the metabolism of trehalose in $R$. etli, including trehalose uptake, degradation, and synthesis (see Figure 2). Our data suggest that uptake and catabolism of trehalose in $R$. etli uses the same pathways as in S. meliloti, since orthologs to the S. meliloti AglEFGK/ThuEFGK ABC trehalose/maltose/sucrose transporters [22,23], as well as the ThuAB catabolic route [21], were found in $R$. etli. In addition, $R$. etli genome accounts for up to 3 putative copies of the trehalose-6-phosphate hydrolase (TreC). Only TreC3 was in the same group as the characterized $\mathrm{TreC}$ protein from $E$. coli, suggesting that the other copies might have a slightly different function. Interestingly, treC2 (annotated as aglA) was located upstream of the aglEFGK genes encoding the alpha-glucoside $\mathrm{ABC}$ transporter. In S. meliloti, aglA, encoding an alpha-glucosidase with homology to family 13 of glycosyl hydrolases, forms part of the aglEFGAK operon, suggesting a possible function in sucrose, maltose and/or trehalose catabolism. Further work is necessary to elucidate the role of the different systems involved in trehalose transport and degradation in R. etli.

Regarding trehalose synthesis, Suarez et al. [10] already suggested the presence in $R$. etli of the three trehalose biosynthetic pathways so far known in rhizobia (OtsAB, TreS, and TreYZ). In this work, we precisely located the corresponding genes, and proposed the most plausible route of glucose synthesis from mannitol, and subsequent OtsABmediated trehalose synthesis (see Figure 2).

We found that genes for trehalose metabolism were scattered in the genome, and sometimes present in more than one copy (i.e., ots A, treZ, treS, treC). This high enzyme redundancy seems to be a general characteristic of $R$. etli CFN 42, and was proposed to correlate with the different degrees of metabolic responses and alternative regulation necessary to cope with a challenging environment without compromising the integrity of the pathways [30]. Despite the active site residues were conserved in the p42a-encoded copy of OtsA, our phylogenetic analysis, together with the presence of insertion sequences flanking the gene, and its different codon used (if compared to the $R$. etli chromosome), strongly suggests that otsAa was acquired by lateral transfer. All these findings agree with the proposal by González et al. [30] about an exogenous origin for $R$ etli $\mathrm{p} 42 \mathrm{a}$.

The role of trehalose in the osmostress response has been widely demonstrated in many bacteria, including $S$. meliloti [5], B. japonicum [2] and R. etli [10]. In the former species, the involvement of trehalose in osmoadaptation was proposed based on three findings: (i) trehalose accumulation in the wild type was osmoregulated, (ii) an otsA mutant was osmosensitive, and (iii) overexpression of otsA led to an increased osmotolerance. Our results confirm the previous result that trehalose biosynthesis in $R$. etli is triggered by osmotic stress. However, the otsAch mutant reported in this work was much less affected by $\mathrm{NaCl}$ stress than the ots $A$ mutant described by Suarez et al. [10]. These authors tested osmosensitivity in a glycerol minimal medium with $0.5 \mathrm{M} \mathrm{NaCl}$ during $48 \mathrm{~h}$. In contrast, we found that the $R$. etli wild type strain could not grow above $0.2 \mathrm{M} \mathrm{NaCl}$ in $\mathrm{B}^{-}$mannitol minimal medium. Therefore, it is possible that the otsAch mutant described here might show an increased osmosensitivity at higher salinities. On the other hand mannitol, which was accumulated as an osmoprotectant (see Figure 4B), might have partially restored the growth of the otsAch strain when it was used as a carbon source.

Notably, extracts of otsAch cells grown with mannitol contained large amounts of glutamate, which was the 
predominant compatible solute (see Figure 4C). Thus, glutamate seems to be important for the long term adaptation of R. etli to osmotic stress, at least in the otsAch mutant strain describe here. Very interestingly, growth of the otsAch mutant was also affected in the absence of salinity stress (see Figure 5 and Additional file 3: Figure S2), suggesting an important role of trehalose in $R$. etli physiology. Trehalose has been described to be essential as cell wall and membrane precursor [59], as membrane stabilizer [60], or as antoxidant [61], to give some examples. This apparent essentiality of trehalose for normal growth of $R$. etli deserves further investigation.

A high level of trehalose accumulation is an important factor in the heat shock response in yeast [25]. In addition, bacteria such as $E$. coli and S. enterica serovar Typhimurium accumulate trehalose in response to heat stresses, and transcription of the ots $A B$ genes for trehalose synthesis is thermoregulated [27,62]. In this work, we show the relevance of trehalose for $R$ etli tolerance to high temperature. Although, trehalose content in $R$. etli cells grown at high temperature was very low, these levels were apparently enough as to protect wild type cells against heat stress, as growth of the trehalose deficient otsAch strain was impaired at high temperature. Similarly in E. coli, stationary phase induced thermotolerance has been shown to depend upon the rpoS regulated expression of the ots $A B$ genes for trehalose synthesis, but the levels of trehalose synthesized on entry into stationary phase were very much lower than in osmotically stressed cells [26]. There is now a large body of evidence showing that the mechanisms for trehalosemediated protection against heat and desiccation stress are different from those involved in osmoprotection, i.e., as a counteracting osmolyte. Thus, studies in vitro have shown that trehalose preserves structure and function in biomolecules and molecular assemblages, such as membranes, during drying and heat stress [63].

Strains of R. leguminosarum bv trifolii [7] and R. etli (this work) deficient in trehalose synthesis are more sensitive to the effects of drying, and show impaired survival upon storage. Thus, desiccation tolerance in $R$. etli cells was dependent of high trehalose production by osmotic pre-conditioned cells. Indeed, desiccation stress is much more harmful than heat stress for microorganisms, as it produces the accumulation of salt and solutes, hyperosmotic stress, metabolism impairment, and damage to macromolecules upon removing the aqueous monolayer [64]. This may explain why high trehalose content is necessary for survival of $R$. etli cells to drying, in order to cope with so many stresses. In agreement with this, E. coli [65], S. meliloti [55], and desert-isolated rhizobial strains nodulating acacia [56] that were osmotically induced to accumulate trehalose (and also mannosucrose, in desert- isolated rhizobia), showed increased tolerance to drying and storage. Interestingly, transcriptomic analyses revealed that desiccation stress per se, if performed under controlled conditions, also induced trehalose synthesis by B. japonicum [24], the soil actinomycete Rhodococcus jostii [66] and the yeast Saccharomyces cerevisiae [67].

It is worth mentioning that desiccation tolerance by $R$. etli was not improved by an increase in drying temperature. This lack of correlation has been also found in many other rhizobia [64] and could be attributed, at least in $R$. etli, to the low induction of trehalose synthesis under high temperature. On the other hand, the survival rate of $R$. etli wild type strain after the vacuum-drying treatments was below $40 \%$, and rapidly decreased after 4 days storage (see Figure 6). This differs from the high survival rates found for $S$. meliloti on nitrocellulose filters [55] or R. leguminosarum bv trifolii on glass beads [7]. Rather than intrinsic tolerance to desiccation, we suggest that these differences may be related to the experimental conditions used for drying.

In rhizobia, the relationship between inactivation of a given trehalose metabolic pathway (and the resulting trehalose accumulation) and the observed symbiotic performance, seems to vary among species (see Introduction). The $R$. etli ots $A$ mutant reported by Suarez et al. [10] was affected in its capacity to establish an efficient symbiosis with bean plants. However, bacteroids of the $R$. etli otsAch mutant constructed in this work showed the same trehalose levels than those of the wild type, and were not affected in its symbiotic performance. The reasons for these differences remain to be elucidated, but it is plausible that under the conditions used in our symbiosis experiments other trehalose synthesis pathways were activated in the otsAch strain, including the otsAa copy, that may compensate the lack of otsAch. Thus, our results do not preclude a role of trehalose in the R. etli-Phaseolus vulgaris symbiosis.

In its natural habitat, soil bacteria as $R$. etli are subjected to fluctuating osmotic, temperature and desiccation constrains. Improving trehalose production in $R$ etli has been shown to be a useful strategy to achieve drought tolerance of the bean plant host [10]. In this work, we have shown that trehalose is essential for $R$. etli survival to high temperature and drying under free living conditions. Thus, engineering trehalose accumulation promises to be useful to improve survival of $R$. etli-based inoculants during desiccation stress in storage, upon application to seeds, or once released in fields.

\section{Conclusions}

In bacteria, hyperosmotic, heat and drought stresses involve a number of multiple and complex responses, which in some cases are interrelated. Desiccation 
tolerance is special, as any response against this stress should be sensed and elicited before the water activity is too low as to respond to. In B. japonicum, controlled desiccation conditions resulted in a significant induction of the ots $A$, ots $B$ and treS genes for trehalose synthesis, as well as increased trehalose levels. However, in Nature drying may be so rapid as to preclude any metabolic response. Thus, it is reasonable to assume that desiccation tolerance may be either a constitutive trait or conditioned to the responses to other stresses such as high salinity, heat, or oxygen stress. In the example illustrated in this work, the disaccharide trehalose was involved in the $R$. etli response to the three stresses, suggesting that it is a common element of the general abiotic stress response of this microorganism. One of the most interesting findings of this study was that high temperature did not induce a dramatic accumulation of trehalose by $R$. etli, although trehalose levels were enough as to cope with high temperature. Thus, our results suggest that selection of heat tolerant strains might not always ensure a concomitant enhanced drought tolerance, at least if the strategy is based upon a higher trehalose accumulation. On the other hand, desiccation seems to be the most deleterious stress for $R$. etli, and apparently demanded a higher, osmotic stress-dependent, trehalose production in order to survive.

\section{Additional files}

\section{Additional file 1: Table S1. R. etli genes involved in trehalose and} glutamate metabolis.

Additional file 2: Figure S1. Genomic analysis of R. etli pathways involved in trehalose metabolism. (A) Genomic context of genes involved in trehalose metabolism. Position and clustering of genes included in Additional file 1: Table S1. are indicated. (B) Neighbor-joining tree based on proteins belonging to families 13 and 15 of glycosydases, including the three TreC-like proteins from $R$. etli. The tree is drawn to scale, with branch lengths in the same units as those of the evolutionary distances used to infer the phylogenetic tree. The E. coli and Rhrodothermus marinus representatives were used as outgroup. The evolutionary distances were computed using the Poisson correction method and are in the units of the number of amino acid substitutions per site. The rate variation among sites was modeled with a gamma distribution (shape parameter $=1$ ). All positions containing gaps and missing data were eliminated from the dataset (complete deletion option). Bootstrap probabilities (as percentage) were determined from 1000 resamplings.

Additional file 3: Figure S2. Growth of R. wild type (WT) and the otsAch mutant CMS310 with trehalose and glucose as the sole carbon source. Cells were grown in at $28^{\circ} \mathrm{C}$ in B- minimal medium with $20 \mathrm{mM}$ trehalose or glucose and 0.0 or $0.2 \mathrm{M} \mathrm{NaCl}$.

\section{Authors' contributions}

MRB and MA performed the majority of the experiments, participated in bioinformatics analysis, study design, and in crafting of the manuscript. $\mathrm{AH}$, MJD and FIG performed symbiosis experiments and RMN analyses. JJN and CV conceived the study, participated in the design, coordination, bioinformatic analysis, and crafting of the manuscript. All authors have read and approved the final manuscript.

\section{Acknowledgments}

We thank personnel at the Mass Spectroscopy (María Eugenia Soria) services of CITIUS (General Research Services, University of Seville) for technical assistance. This research was financially supported by grants from the CYTED (AGROSEQ; 107PIC0312), Spanish Ministerio de Ciencia e Innovación (BIO2011-22833), Spanish National Network on Extremophilic Microorganisms (BIO2011-12879-E), and Junta de Andalucía (P08-CVI-03724). Mercedes ReinaBueno was recipient of a fellowship from the Spanish Ministerio de Ciencia e Innovación. Montserrat Argandoña holds a postdoctoral contract from Junta de Andalucía.

\section{Author details}

'Department of Microbiology and Parasitology, Faculty of Pharmacy, University of Seville, Profesor García González 2, Seville 41012, Spain. ${ }^{2}$ Department of Organic and Pharmaceutical Chemistry, Faculty of Pharmacy,

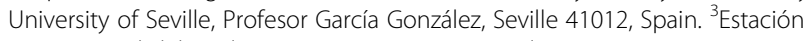
Experimental del Zaidín, CSIC, PO Box 419, Granada 18080, Spain.

Received: 25 February 2012 Accepted: 12 September 2012

Published: 17 September 2012

\section{References}

1. Miller KJ, Wood JM: Osmoadaptation by rhizosphere bacteria. Annu Rev Microbiol 1996, 50:101-136.

2. Sugawara M, Cytryn EJ, Sadowsky MJ: Functional role of Bradyrhizobium japonicum trehalose biosynthesis and metabolism genes during physiological stress and nodulation. Appl Environ Microbiol 2010, 76:1071-1081.

3. da Costa MS, Santos H, Galinski EA: An overview of the role and diversity of compatible solutes in Bacteria and Archaea. Adv Biochem Eng Biotechnol 1998, 61:117-153.

4. Welsh DT: Ecological significance of compatible solute accumulation by micro organisms: from single cells to global climate. FEMS Microbiol Rev 2000, 24:263-290.

5. Domínguez-Ferreras A, Soto MJ, Pérez-Arnedo R, Olivares J, Sanjuán J: Importance of trehalose biosynthesis for Sinorhizobium meliloti osmotolerance and nodulation of Alfalfa roots. J Bacterio/ 2009, 191:7490-7499.

6. Fernandez-Aunión C, Hamouda TB, Iglesias-Guerra F, Argandoña M, ReinaBueno M, Nieto JJ, Aouani ME, Vargas C: Biosynthesis of compatible solutes in rhizobial strains isolated from Phaseolus vulgaris nodules in Tunisian fields. BMC Microbiol 2010, 10:192.

7. Mclntyre HJ, Davies H, Hore TA, Miller SH, Dufour JP, Ronson CW: Trehalose biosynthesis in Rhizobium leguminosarum bv. trifolii and its role in desiccation tolerance. Appl Environ Microbiol 2007, 73:3984-3992.

8. Streeter JG: Accumulation of alpha, alpha-trehalose by Rhizobium bacteria and bacteroids. J Bacterio/ 1985, 164:78-84.

9. Talibart R, Jebbar M, Gouffi K, Pichereau V, Gouesbet G, Blanco C, Bernard T, Pocard J: Transient accumulation of glycine betaine and dynamics of endogenous osmolytes in salt-stressed Cultures of Sinorhizobium meliloti. Appl Environ Microbiol 1997, 63:4657-4663.

10. Suárez R, Wong A, Ramírez M, Barraza A, Orozco Mdel C, Cevallos MA, Lara M, Hernández G, Iturriaga G: Improvement of drought tolerance and grain yield in common bean by overexpressing trehalose-6-phosphate synthase in rhizobia. Mol Plant Microb Interact 2008, 21:958-966.

11. De Smet KA, Weston A, Brown IN, Young DB, Robertson BD: Three pathways for trehalose biosynthesis in mycobacteria. Microbiology 2000, 146:199-208.

12. Maruta K, Hattori K, Nakada T, Kubota M, Sugimoto T, Kurimoto M: Cloning and sequencing of trehalose biosynthesis genes from Rhizobium sp. M-11. Biosci Biotechnol Biochim 1996, 60:717-720.

13. Maruta K, Hattori K, Nakada T, Kubota M, Chaen H, Fukuda S, Sugimoto T, Kurimoto M: Cloning and sequencing of cluster of genes encoding novel enzymes of trehalose biosynthesis from thermophilic archaebacterium Sulfolobus acidocaldarius. Biochim Biophys Acta 1996, 1291:177-181.

14. Streeter JG: Seasonal distribution of carbohydrates in nodules and stem exudate from field-grown soya bean plants. Ann Bot 1981, 48:441-450

15. Thevelein JM: Regulation of trehalose movilization in fungi. Microbio/ Rev 1984, 48:42-59. 
16. Henrissat B, Bairoch A: New families in the classification of glycosyl hydrolases based on amino acid sequence similarities. Biochem J 1993, 293:781-788.

17. Carroll JD, Pastuszak I, Edavana VK, Pan YT: A novel trehalase from Mycobacterium smegmatis - purification, properties, requirements. FEBS J 2007, 274:1701-1714.

18. Wannet WJ, Op den Camp HJ, Wisselink HW, van der Drift C, Van Griensven $\sqcup$, Vogels GD: Purification and characterization of trehalose phosphorylase from the commercial mushroom Agaricus bisporus. Biochim Biophys Acta 1998, 1425:177-188.

19. Andersson U, Levander F, Rådström P: Trehalose-6-phosphate phosphorylase is part of a novel metabolic pathway for trehalose utilization in Lactococcus lactis. J Biol Chem 2001, 276:42707-42713.

20. Streeter JG: Enzymes of sucrose, maltose, and a, a-trehalose catabolism in soybean root nodules. Planta 1982, 155:112-115.

21. Jensen JB, Ampomah OY, Darrah R, Peters NK, Bhuvaneswari TV: Role of trehalose transport and utilization in Sinorhizobium meliloti-alfalfa interactions. Mol Plant Microb Interact 2005, 18:694-702.

22. Jensen JB, Peters NK, Bhuvaneswari TV: Redundancy in periplasmic binding protein-dependent transport systems for trehalose, sucrose, and maltose in Sinorhizobium meliloti. I Bacteriol 2002, 184:2978-2986.

23. Willis LB, Walker GC: A novel Sinorhizobium meliloti operon encodes an alpha-glucosidase and a periplasmic-binding-protein-dependent transport system for alpha-glucosides. J Bacteriol 1999, 181:4176-4184.

24. Cytryn EJ, Sangurdekar DP, Streeter JG, Franck WL, Chang WS, Stacey G, Emerich DW, Joshi T, Xu D, Sadowsky MJ: Transcriptional and physiological responses of Bradyrhizobium japonicum to desiccationinduced stress. J Bacteriol 2007, 189:6751-6762.

25. de Virgilio C, Hottiger T, Dominguez J, Boller T, Wiemken A: The role of trehalose synthesis for the adquisition of thermotolerance in yeast. I. Genetic evidence that trehalose is a thermoprotectant. Eur J Biochem 1994, 219:179-186.

26. Hengge-Aronis R, Klein W, Lange R, Rimmele M, Boos W: Trehalose synthesis genes are controlled by the putative sigma factor encoded by rpoS and are involved in stationary-phase thermotolerante in Escherichia coli. J Bacterio/ 1991, 173:7918-7924.

27. Cánovas D, Fletcher SA, Hayashi M, Csonka LN: Role of trehalose in growth at high temperature of Salmonella enterica serovar Typhimurium. J Bacteriol 2001, 183:3365-3371.

28. Vargas C, Argandoña M, Reina-Bueno M, Rodríguez-Moya J, Fernández Aunión C, Nieto JJ: Unravelling the adaptation responses to osmotic and temperature stress in Chromohalobacter salexigens, a bacterium with broad salinity tolerance. Saline Systems 2008, 4:14

29. Segovia L, Young PW, Martínez-Romero E: Reclassification of American Rhizobium leguminosarum Biovar Phaseoli type I strains as Rhizobium etli sp. nov. Int J Syst Bacteriol 1993, 43:374-377.

30. González V, Santamaría RI, Bustos P, Hernández-González I, Medrano-Soto A, Moreno-Hagelsieb E, Janga SC, Ramírez MA, Jiménez-Jacinto V, ColladoVides J, Dávila G: The partitioned Rhizobium etli genome: Genetic and metabolic redundancy in seven interacting replicons. Proc Natl Acad Sci USA 2006, 103:3834-3839.

31. Noel KD, Sanchez A, Fernandez L, Leemans J, Cevallos MA: Rhizobium phaseoli symbiotic mutants with transposon Tn5 insertions. J Bacteriol 1984, 158:148-155.

32. Beringer JE: $\mathrm{R}$ factor transfer in Rhizobium leguminosarum. J Gen Microbiol 1974, 84:188-198.

33. Miller JH: A Short Course in Bacterial Genetics. Cold Spring Harbor, NY: Cold Spring Harbor Laboratory; 1992

34. Spaink HP, Aarts A, Stacey G, Bloemberg GV, Lugtenberg BJ, Kennedy EP: Detection and separation of Rhizobium and Bradyrhizobium Nod metabolites using thin-layer chromatography. Mol Plant Microbe Interact 1992, 5:72-80

35. Hanahan D: Studies on transformation of Escherichia coli with plasmids. J Mol Biol 1983, 166:557-580.

36. Prentki $\mathrm{P}, \mathrm{Krish} \mathrm{HM}$ : In vitro insertional mutagenesis with a selectable DNA fragment. Gene 1984, 29:303-313.

37. Kessler B, de Lorenzo V, Timmis KN: A general system to integrate lacZ fusion into the chromosome of gram negative bacteria: regulation of the Pm promoter of the TOL plasmid studied with all controlling elements in monocopy. Mol Gen Genet 1992, 233:293-301.
38. Quandt J, Hynes MF: Versatile suicide vectors which allow direct selection for gene replacement in gram-negative bacteria. Gene 1993, 127:15-21.

39. Manzanera M, García de Castro A, Tøndervik A, Rayner-Brandes M, Strøm AR, Tunnacliffe A: Hydroxyectoine is superior to trehalose for anhydrobiotic engineering of Pseudomonas putida KT2440. Appl Environ Microbiol 2002, 68:4328-4333.

40. Blázquez MA, Stucka R, Feldmann H, Gancedo C: Trehalose-6-P synthase is dispensable for growth on glucose but not for spore germination in Schizosaccharomycespombe. J Bacteriol 1994, 176:3895-3902.

41. Delgado MJ, Ligero F, Lluch C: Effect of salt stress on growth and nitrogen fixation by pea, faba bean, common bean and soybean plants. Soil Biol Biochem 1994, 26:371-376.

42. García-Estepa R, Argandoña M, Reina-Bueno M, Capote N, Iglesias-Guerra F, Nieto JJ, Vargas C: The ectD gene, which is involved in the synthesis of the compatible solute hydroxyectoine, is essential for thermoprotection of the halophilic bacterium Chromohalobacter salexigens. J Bacterio/ 2006, 188:3774-3784.

43. Vargas C, Coronado MJ, Ventosa A, Nieto JJ: Host range, stability, and compatibility of broad host-range-plasmids and a shuttle vector in moderately halophilic bacteria. Evidence of intragenic and intergenic conjugation in moderate halophiles. Syst Appl Microbiol 1997, 20:173-181.

44. Kanehisa M, Goto S, Kawashima S, Okuno Y, Hattori M: The KEGG resource for deciphering the genome. Nucleic Acids Res 2004, 32:D277-D280.

45. Caspi R, Altman T, Dreher K, Fulcher CA, Subhraveti P, Keseler IM, Kothari A, Krummenacker M, Latendresse M, Mueller LA, Ong Q, Paley S, Pujar A, Shearer AG, Travers M, Weerasinghe D, Zhang P, Karp PD: The MetaCyc database of metabolic pathways and enzymes and the BioCyc collection of pathway/genome databases. Nucleic Acids Res 2012, 40:D742-D753.

46. Tamura K, Peterson D, Peterson N, Stecher G, Nei M, Kumar S: MEGA5: molecular evolutionary genetics analysis using maximum likelihood, evolutionary distance, and maximum parsimony methods. Mol Biol Evol 2011, 28:2731-2739.

47. Saitou N, Nei M: The neighbor-joining method: a new method for reconstructing phylogenetic trees. Mol Biol Evol 1987, 4:406-425.

48. Felsenstein J: Confidence limits on phylogenies: an approach using the bootstrap. Evolution 1985, 39:783-791.

49. Peralta H, Mora Y, Salazar E, Encarnación S, Palacios S, Mora1 J: Engineering the nifH promoter region and abolishing poly- $\beta$-hydroxybutyrate accumulation in Rhizobium etli enhance nitrogen fixation in symbiosis with Phaseolus vulgaris. App Environ Microbiol 2004, 70:3272-3281.

50. Rigaud J, Puppo A: Indole-3 acetic catabolism by soybean bacteroids. J Gen Bacteriol 1975, 88:223-228.

51. Brouat A, Crouzet C: Notes techniques sur un appareil semiautomatique de clorage de l'azote et de certains composés volatiles. Plant Physiology 1965, 58:438-446.

52. LaRue TA, Child JJ: Sensitive fluorometric assay for leghaemoglobin. Anal Biochem 1979, 92:11-15.

53. Boboye B: Degradation of trehalose by rhizobia and characteristics of a trehalose-degrading enzyme isolated from Rhizobium species NGR234. J Appl Microbiol 2004, 97:256-261.

54. Gibson RP, Turkenburg JP, Charnock SJ, Lloyd R, Davies GJ: Insights into trehalose synthesis provided by the structure of the retaining glucosyltransferase OtsA. Chem Biol 2002, 9:1337-1346.

55. Vriezen JA, de Bruijn FJ, Nüsslein K: Desiccation responses and survival of Sinorhizobium meliloti USDA 1021 in relation to growth phase, temperature, chloride and sulfate availability. Lett Appl Microbio/ 2006, 42:172-178.

56. Essendoubi M, Brhada F, Eljamali JE, Filali-Maltouf A, Bonnassie S, Georgeault S, Blanco C, Jebbar M: Osmoadaptative responses in the rhizobia nodulating Acacia isolated from south-eastern Moroccan Sahara. Environ Microbiol 2007, 9:603-611.

57. Resendis-Antonio O, Reed JL, Encarnación S, Collado-Vides J, Palsson BØ: Metabolic reconstruction and modeling of nitrogen fixation in Rhizobium etli. PLoS Comput Biol 2007, 3:1887-1895.

58. Resendis-Antonio O, Hernández M, Salazar E, Contreras S, Batallar GM, Mora $Y$, Encarnación S: Systems biology of bacterial nitrogen fixation: high-throughput technology and its integrative description with constraint-based modeling. BMC Syst Biol 2011, 5:120.

59. Tzvetkov M, Klopprogge C, Zelder O, Liebl W: Genetic dissection of trehalose biosynthesis in Corynebacterium glutamicum: inactivationof 
trehalose production leads to impaired growth and an altered cell wall lipid composition. Microbiology 2003, 149:1659-1673.

60. Albertorio F, Chapa VA, Chen X, Diaz AJ, Cremer PS: The alpha, alpha-(1->1) linkage of trehalose is key to anhydrobiotic preservation. J Am Chem Soc 2007, 129:10567-10574.

61. Benaroudj N, Lee DH, Goldberg AL: Trehalose accumulation during cellular stress protects cells and cellular proteins from damage by oxygen radicals. J Biol Chem 2001, 276:24261-24267.

62. Gunasekera TS, Csonka LN, Paliy O: Genome-wide transcriptional responses of Escherichia coli K-12 to continuous osmotic and heat stresses. J Bacteriol 2008, 10:3712-3720.

63. Ricker JV, Tsvetkova NM, Wolkers WF, Leidy C, Tablin F, Longo M, Crowe JH: Trehalose maintains phase separation in an air-dried binary lipid mixture. Biophys J 2003, 84:3045-3051.

64. Vriezen JA, de Bruijn FJ, Nüsslein K: Responses of rhizobia to desiccation in relation to osmotic stress, oxygen, and temperature. Appl Environ Microbiol 2007, 73:3451-3459.

65. Welsh DT, Herbert RA: Osmotically induced intracellular trehalose, but not glycine betaine accumulation promotes desiccation tolerance in Escherichia coli. FEMS Microbiol Lett 1999, 74:57-63.

66. LeBlanc JC, Gonçalves ER, Mohn WW: Global response to desiccation stress in the soil actinomycete Rhodococcus jostii RHA1. Appl Environ Microbiol 2008, 74:2627-2636.

67. Singh J, Kumar D, Ramakrishnan N, Singhal V, Jervis J, Garst JF, Slaughter SM, DeSantis AM, Potts M, Helm RF: Transcriptional response of Saccharomyces cerevisiae to desiccation and rehydration. Appl Environ Microbiol 2005, 71:8752-8763.

doi:10.1186/1471-2180-12-207

Cite this article as: Reina-Bueno et al: Role of trehalose in heat and desiccation tolerance in the soil bacterium Rhizobium etli. BMC Microbiology 2012 12:207.

\section{Submit your next manuscript to BioMed Central and take full advantage of:}

- Convenient online submission

- Thorough peer review

- No space constraints or color figure charges

- Immediate publication on acceptance

- Inclusion in PubMed, CAS, Scopus and Google Scholar

- Research which is freely available for redistribution 